\title{
EFFECTS OF FRICTION AND THICKNESS ON LONG-TERM CONSOLIDATION BEHAVIOR OF OSAKA BAY CLAYS
}

\author{
YoIchi WATABE ${ }^{\text {i) }}$, KAORU UdAKA ${ }^{\text {ii) }}$, MASAKI KOBAYASHi ${ }^{\text {iii), }}$ \\ TAKECHIHO TABATA ${ }^{\text {iv) }}$ and TSUYOSHI EMURA ${ }^{v}$
}

\begin{abstract}
The objective of this study is to empirically clarify the scale effect in long-term consolidation behavior. Frictional pressure loss arising at the interface between the consolidation ring and the specimen must be considered, when the specimen thickness increases. This study uses a special oedometer that can evaluate the quantity of the frictional pressure loss. Incremental loading oedometer tests are carried out in order to evaluate the frictional pressure loss in the normal oedometer test using a specimen with a height of $20 \mathrm{~mm}$. The frictional pressure loss ratio generally exceeds 0.2 when the consolidation pressure is less than approximately $300 \mathrm{kPa}$, rather than the overconsolidation range. Consequently, a series of inter-connected type consolidation tests, in which the frictional pressure loss can be minimized by limiting the thickness of each specimen element, are carried out in order to investigate the scale effect of the specimen thickness in the range of 20-200 mm. The end of primary consolidation (EOP) can be clearly identified in the excess pore pressure dissipation. The law of squared $H$ is essentially valid for the pore water pressure dissipation. However, the EOP becomes unclear in the strains when the specimen thickness decreases. The compressive strain at the EOP stays constant or slightly increases with the specimen thickness.
\end{abstract}

Key words: clay, friction, long-term consolidation, primary consolidation, secondary consolidation, thickness (IGC: D5)

\section{INTRODUCTION}

The Kansai International Airport is situated on a large manmade island created by reclaiming a thick subsoil clay deposit in Osaka Bay. The residual settlement that occurred after the inauguration of the airport mainly in the deep and stiff Pleistocene clay deposit cannot be controlled because ground systems cannot be improved at large depths. Therefore, the evaluation of the long-term settlement is an important issue.

Generally, the consolidation test is conducted using a specimen with small dimensions, e.g., thickness of $20 \mathrm{~mm}$ and diameter of $60 \mathrm{~mm}$. The test result is used to predict the in situ consolidation settlement of thick clay deposits. The consolidation test is not an element test but a type of boundary-value problem. Therefore, the scale/thickness effect must be considered. In Terzaghi's one-dimensional consolidation theory, the required consolidation time is proportional to the square of the maximum drainage distance, i.e., the law of squared $H$. The scale-effect relationship between the consolidation behaviors observed in the field and the laboratory has not yet been clarified. Ladd et al. (1977) and Jamiolkowski et al. (1985) have pointed out and explained this relationship by using the two hypotheses shown in Fig. 1:

In hypothesis $\mathrm{A}$, the creep compression occurs only

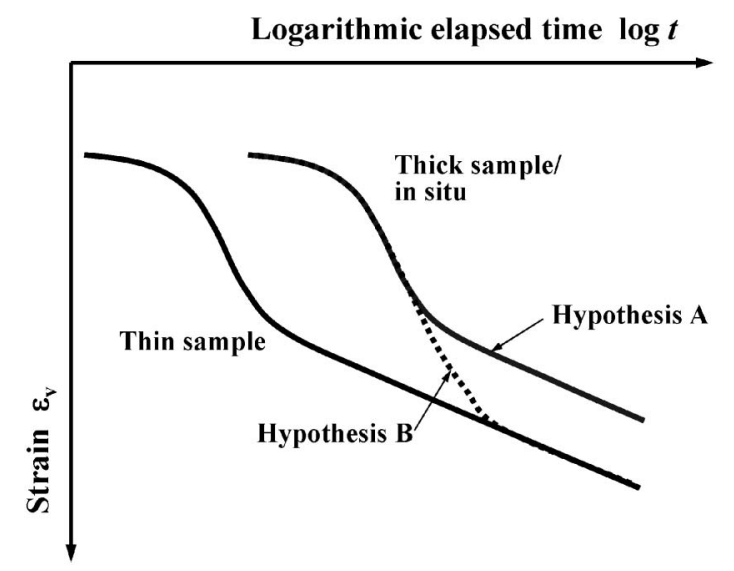

Fig. 1. Comparison between consolidation curves of a thin specimen and a thick specimen/in situ deposit

i) Leader, Soil Mechanics and Geo-environment Research Group, Port and Airport Research Institute, Japan (watabe@ipc.pari.go.jp).

ii) Tokyo Geotechnical Center, OYO Corporation, Japan.

iii) Coastal Development Institute of Technology, Japan.

iv) Kansai International Airport Land Development Co., Ltd., Japan.

v) Kansai International Airport Co., Ltd., Japan.

The manuscript for this paper was received for review on November 22, 2007; approved on May $28,2008$.

Written discussions on this paper should be submitted before March 1, 2009 to the Japanese Geotechnical Society, 4-38-2, Sengoku, Bunkyo-

$\mathrm{ku}$, Tokyo 112-0011, Japan. Upon request the closing date may be extended one month. 
after the end of primary consolidation (EOP). Therefore, the law of squared $H$ is applicable, resulting in the same value of the compressive strain at EOP in both the field and the laboratory. In contrast, in hypothesis B, the creep compression occurs even during the dissipation of excess pore water pressure and is governed by structural viscosity. Therefore, the law of squared $H$ is not applicable, resulting in a large compressive strain with the thickness. The scale effect on the consolidation behavior has not yet been clarified. Many studies have been conducted and reported on the scale effect, such as Berre and Iversen (1972), Aboshi (1973), Ladd et al. (1977), Jamiolkowski et al. (1985), Mesri and Choi (1985), Imai and Tang (1992), Yin et al. (1994), Imai et al. (2003), Tanaka (2005), and Leroueil (2006).

The objective of this study is to empirically clarify the scale effect. Frictional pressure loss arising at the interface between the consolidation ring and the specimen must be considered, when the specimen thickness increases. This study uses a special oedometer that can evaluate the quantity of the frictional pressure loss. Incremental loading oedometer tests are carried out in order to evaluate the frictional pressure loss in the normal oedometer test using a specimen with a height of $20 \mathrm{~mm}$. Additionally, long-term consolidation tests are carried out by focusing on the secondary consolidation. For comparison, long-term triaxial $K_{0}$ consolidation tests are carried out as frictionless tests. Consequently, a series of inter-connected type consolidation tests, in which the frictional pressure loss can be minimized by limiting the thickness of each specimen element, are carried out in order to investigate the scale effect of the specimen thickness in the range of $20-200 \mathrm{~mm}$.

\section{EFFECT OF FRICTION ON THE CONSOLIDATION BEHAVIOR}

\section{Background and Objective}

In an oedometer test, in which a specimen is inserted into a consolidation ring, it is considered that the consolidation pressure applied to the top of the specimen is not sufficiently transferred to the bottom of the specimen, because the frictional pressure loss becomes significant with the specimen thickness. Even in a normal oedometer test using a small specimen, the frictional pressure loss may be inevitable. The effect of the frictional pressure loss on the consolidation behavior has been studied (Yamanouchi and Yasuhara, 1975; Sato et al., 1999; Okai et al., 1999; Sivrikaya and Togrol, 2006). These studies indicate that the frictional pressure loss is significant in the overconsolidation range, and the loss increases with time even in the normal consolidation range. The secondary consolidation, even in the normal consolidation range is possibly underestimated because of the frictional pressure loss. Therefore, we are interested in determining whether the frictional pressure loss significantly affects the long-term consolidation behavior. This chapter aims to evaluate the effect of the frictional pressure loss, which is inevitable in the consolidation test using the

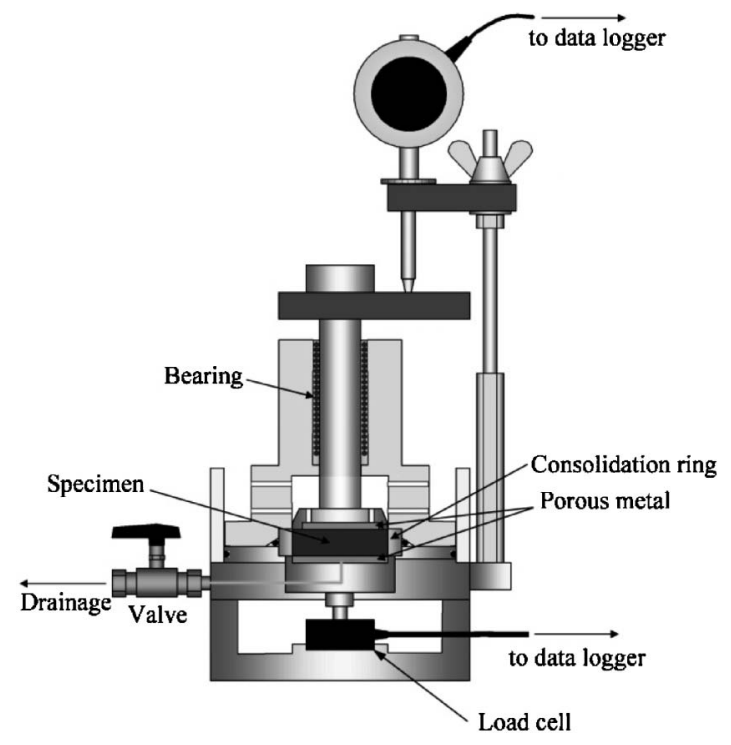

Fig. 2. Special oedometer to evaluate the frictional pressure loss

rigid consolidation ring.

Incremental Loading Oedometer Test with Evaluation of Frictional Pressure Loss

A series of incremental loading oedometer tests using the special oedometer was carried out on Osaka Bay clays retrieved from the Kansai International Airport. The special oedometer is shown in Fig. 2. A load cell is installed at the base to measure the reactive force of the consolidation pressure transmitted to the bottom of the specimen. The frictional pressure loss is defined as the difference between the load applied to the top of the specimen $(P)$ and the reactive force $(R)$ per cross sectional area. Here, the frictional pressure loss ratio $r$ is defined as follows:

$$
r=\frac{P-R}{P}
$$

The consolidation ring in the inner diameter of $60 \mathrm{~mm}$ and height of $20 \mathrm{~mm}$ is made of rigid stainless steel. Porous metal plates are installed at both the top and bottom of the specimen to create double drainage boundaries. Consolidation pressure is applied by counter weights through a lever system. Consolidation settlement is measured by using a linear gauge with a capacity of $20 \mathrm{~mm}$ and accuracy of $0.001 \mathrm{~mm}$.

The soil samples examined in this test series were undisturbed Osaka Bay clays (Ma12, Ma7, Ma4, Ma3, and Ma2) retrieved from the second phase construction site of the Kansai International Airport. The water depth at this site was approximately $19 \mathrm{~m}$. The soil properties are listed in Table 1. Consolidation pressure was loaded incrementally in an incremental pressure ratio $\Delta p / p$ of unity, i.e., at 39, 78, 157, 314, 628, 1256, 2511, 5023, and 10045 $\mathrm{kPa}$. The duration of each loading stage was $24 \mathrm{~h}$.

As an example of the test results, the temporal variations in $r$ for Ma12 are shown in Fig. 3. At each loading stage, $r$ tends to increase with time. If the coefficient of friction is constant, the frictional force arising at the in- 
Table 1. Physical and consolidation properties of the clay samples for the incremental loading oedometer test

\begin{tabular}{lrrrrr}
\hline & Ma12 & Ma7 & Ma4 & Ma3 & Ma2 \\
\hline Depth $z(\mathrm{CDL}-\mathrm{m})$ & 73 & 223 & 264 & 283 & 305 \\
Overburden effective stress $\sigma_{\mathrm{v} 0}^{\prime}(\mathrm{kPa})$ & 365 & 1457 & 1802 & 1937 & 2102 \\
Consolidation yield stress $p_{\mathrm{c}}(\mathrm{kPa})$ & 530 & 1887 & 2512 & 2627 & 3141 \\
Overconsolidation ratio OCR & 1.45 & 1.30 & 1.39 & 1.36 & 1.49 \\
Soil particle density $\rho_{\mathrm{s}}\left(\mathrm{g} / \mathrm{cm}^{3}\right)$ & 2.66 & 2.70 & 2.67 & 2.70 & 2.66 \\
Liquid limit $w_{\mathrm{L}}(\%)$ & 99.8 & 100.4 & 93.6 & 82.4 & 83.6 \\
Plastic limit $w_{\mathrm{P}}(\%)$ & 37.8 & 37.8 & 35.3 & 35.7 & 32.7 \\
Plasticity index $I_{\mathrm{p}}$ & 62.0 & 62.6 & 58.3 & 46.7 & 50.9 \\
Natural water content $w_{\mathrm{n}}(\%)$ & 69.1 & 51.7 & 42.4 & 36.6 & 51.8 \\
\hline
\end{tabular}

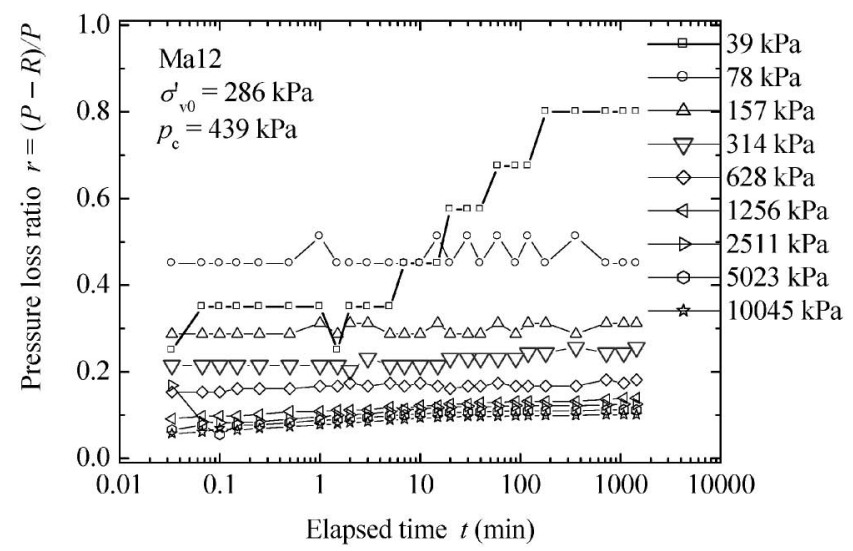

Fig. 3. Temporal variations in pressure loss ratio for Ma12

terface between the consolidation ring and the specimen increases with the effective stress, which increases with the dissipation of excess pore water pressure. The frictional pressure loss ratio $r$ increases with the overconsolidation level; for example, it is 0.8 at $39 \mathrm{kPa}$ (overconsolidation ratio $\mathrm{OCR}=11)$ and 0.45 at $78 \mathrm{kPa}(\mathrm{OCR}=5.6)$. In the normal consolidation range, however, $r$ is in the range of $0.1-0.15$. These qualitative tendencies are consistent with those of the previous studies.

Figure 4 shows the relationships between $r$ and the consolidation pressure $p$ for all the samples. It can be stated that $r$ generally becomes greater than 0.2 in a range of $p$ less than approximately $300 \mathrm{kPa}$, rather than in a range of overconsolidation. However, this is not significant in an engineering sense because the strain at $300 \mathrm{kPa}$ in the overconsolidation range is very small even for Ma12 with the smallest consolidation yield stress among the clays examined in this study. This fact indicates that it is not necessary to correct the effect of the frictional pressure loss for the test results in the practical prediction of consolidation settlement.

Compression curves $(e-\log p)$ are drawn in Fig. 5; here, a pair of $e-\log p$ curves for each sample correspond to the original curve and corrected curve. The pressure $p$ for the latter is defined as the average of the consolidation pressure applied to the top of the specimen and the pressure transmitted to the bottom of the specimen. The influence of the frictional pressure loss for the 20-mm-thick specimen in the incremental loading oedom-

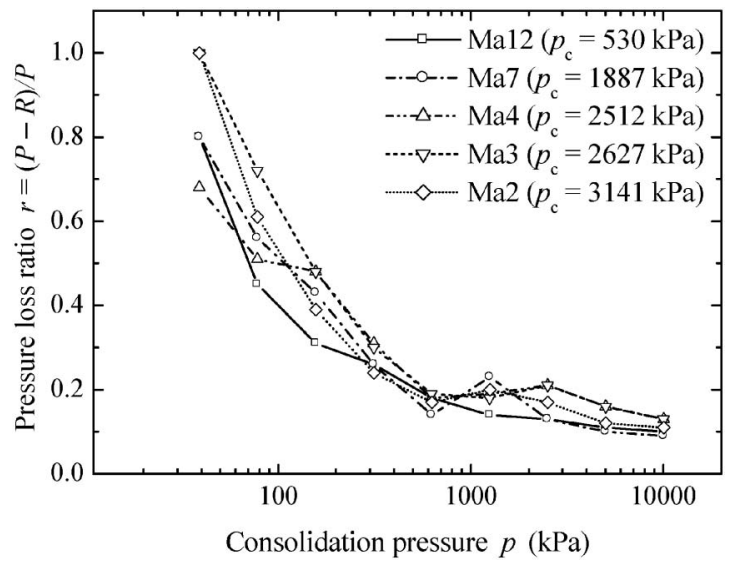

Fig. 4. Relationships between pressure loss ratio and consolidation pressure

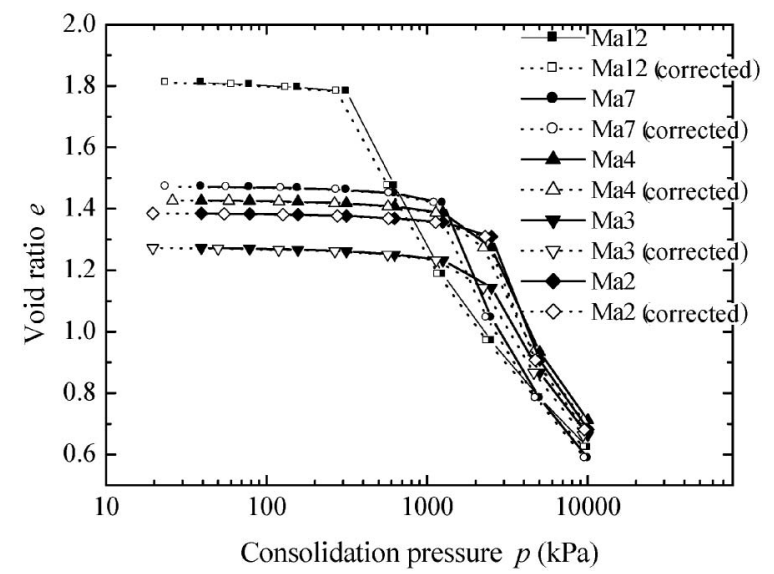

Fig. 5. Compression curves $(e-\log p)$ with and without correction for frictional pressure loss

eter test on the compression curve is not significant for the clays examined in this study, even in the normal consolidation range where consolidation settlement is important in engineering practice.

As mentioned above, the effect of the frictional pressure loss is negligible in 24-h loading. However, as shown in Fig. 3, $r$ tends to increase with time. This affects secondary consolidation, as discussed in the next section.

\section{Long-term Consolidation Test with Evaluation of Fric-} tional Pressure Loss

A long-term consolidation test using the special oedometer (Fig. 2) was also carried out. An undisturbed Ma12 sample described in Table 1 was examined. From a constant rate of strain consolidation test, separately carried out at a strain rate of $3.3 \times 10^{-6} \mathrm{~s}^{-1}$, the consolidation yield stress $p_{\mathrm{c}}$ was obtained as $465 \mathrm{kPa}$ for the sample. The long-term consolidation test (20-day loading) was carried out under a consolidation pressure of 358 $\mathrm{kPa}\left(=\right.$ overburden effective stress $\left.\sigma_{\mathrm{v} 0}^{\prime}\right), 412 \mathrm{kPa}\left(=\left(\sigma_{\mathrm{v} 0}^{\prime}+\right.\right.$ $\left.\left.p_{\mathrm{c}}\right) / 2\right), 465 \mathrm{kPa}\left(=p_{\mathrm{c}}\right)$, and $646 \mathrm{kPa}\left(=1.4 p_{\mathrm{c}}\right)$, respectively. Preliminary consolidation pressures up to $\sigma_{\mathrm{v} 0}^{\prime}$ were applied incrementally in three stages. The loading condi- 
Table 2. Loading conditions for the long-term consolidation test

\begin{tabular}{ccccc}
\hline \multirow{3}{*}{$\begin{array}{c}\text { Sample name } \\
\text { and depth } \\
z(\mathrm{CDL}-\mathrm{m})\end{array}$} & $\begin{array}{c}\text { 1st stage } \\
(\mathrm{kPa})\end{array}$ & $\begin{array}{c}\text { 2nd stage } \\
\sigma_{\mathrm{v} 0}^{\prime} / 2(\mathrm{kPa})\end{array}$ & $\begin{array}{c}\text { 3rd stage } \\
\sigma_{\mathrm{v} 0}^{\prime}(\mathrm{kPa})\end{array}$ & $\begin{array}{c}\text { Long-term } \\
\text { pressure } \\
p(\mathrm{kPa})\end{array}$ \\
\hline & & & & 358 \\
\hline $\begin{array}{c}\text { Ma12 } \\
(-66.5 \mathrm{~m})\end{array}$ & $\begin{array}{c}39 \\
(2 \mathrm{~h})\end{array}$ & $\begin{array}{c}179 \\
(1 \text { day })\end{array}$ & $\begin{array}{c}358 \\
(1 \text { day })\end{array}$ & $\frac{412}{465}$ \\
\hline
\end{tabular}

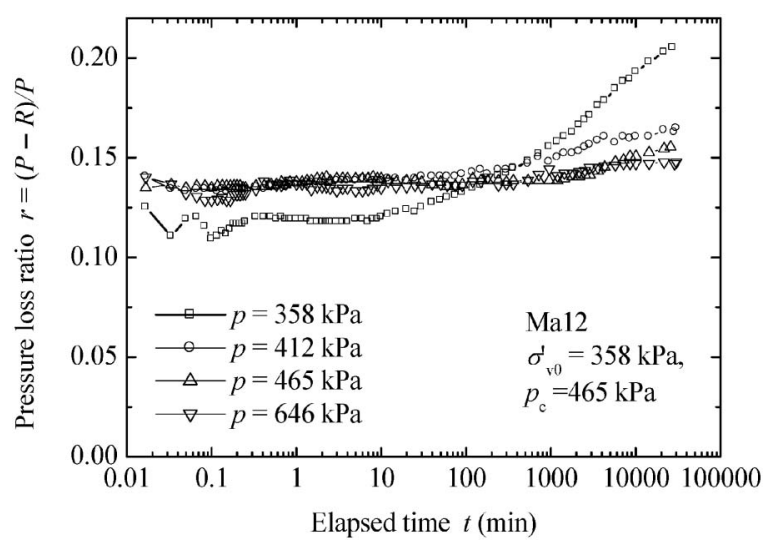

Fig. 6. Temporal variations of the frictional pressure loss ratio

tions are summarized in Table 2.

Temporal variations in $r$ are shown in Fig. 6. At the beginning, corresponding to the primary consolidation stage, the ratio $r$ is in the range of 0.12-0.14. During the secondary consolidation stage, however, $r$ tends to increase. At $\sigma_{v_{0}}^{\prime}$ in the overconsolidation range ( $\left.358 \mathrm{kPa}\right), r$ exceeds 0.2 and it significantly increases with time. In contrast, in the normal consolidation range, $r$ during the secondary consolidation is at most approximately 0.15 . Because the frictional pressure loss is defined as the differential pressure at the top and bottom of the specimen, the substantive value of the frictional pressure loss ratio $\left(r^{\prime}\right)$ at half the specimen height is approximately half of $r$, i.e., $r^{\prime} \approx r / 2$. Therefore, the frictional pressure loss may be significant in the overconsolidation range; however, it is essentially negligible in the normal consolidation range $\left(r^{\prime}<0.075\right)$.

\section{Long-term Ttriaxial $K_{0}$ Consolidation Test}

In the above test series, the frictional pressure loss arising at the interface between the specimen and the consolidation ring was evaluated in order to investigate the effect on the long-term consolidation behavior. A consolidation test without the frictional pressure loss can be conducted as a $K_{0}$ consolidation test by means of a triaxial cell. Long-term triaxial $K_{0}$ consolidation tests were carried out and their results were compared with those of the above tests.

The tests were conducted with the triaxial apparatus used in Watabe et al. (2003). The system, designed for a

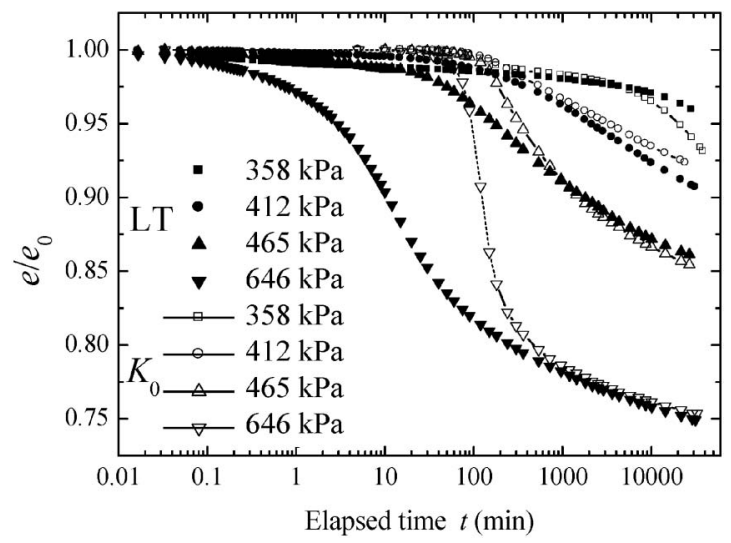

Fig. 7. Temporal variations of the void ratio obtained from the triaxial $K_{0}$ consolidaiton test in comparison with the results of the longterm oedometer tests

$K_{0}$ consolidation test of saturated clay, can control the cell pressure such that the radial strain calculated from both the axial strain and drainage is maintained at zero by a feedback system, while increasing the axial pressure at a constant rate. The radial strain could be maintained within $\pm 0.04 \%$ which generally does not affect the $K_{0}$ value (coefficient of earth pressure at rest).

Drain paper is generally used in the triaxial test of the clay specimen to accelerate the consolidation and homogenize the pore pressure. When we use a relationship calibrated previously between the cell pressure and the drainage from the paper, the existence of the drain paper does not affect the accuracy of the $K_{0}$ consolidation test result (Tsuchida and Kikuchi, 1991; Watabe et al., 2003). The $K_{0}$ consolidation test in this study was different from the ordinary $K_{0}$ consolidation test, which is conducted as a preliminary consolidation test for shearing. Because it focuses on the long-term consolidation behavior in the secondary consolidation stage with a minute amount of drainage, it is ideal to exclude uncertainties. Therefore, we carried out the triaxial $K_{0}$ consolidation test in the single drainage condition without the drain paper for a specimen that was trimmed such that it had a diameter of $60 \mathrm{~mm}$ and a height of $20 \mathrm{~mm}$, following the method of some tests described in Watabe et al. (2003).

In the triaxial $K_{0}$-consolidation tests, back pressure of $98 \mathrm{kPa}$ was applied. The clay sample and loading conditions were the same as those mentioned in the previous section (Table 2).

The results are shown in the following part in comparison with the results of the long-term oedometer tests. The temporal variations of the void ratio are shown in Fig. 7. The void ratio $e$ is divided by the initial void ratio $e_{0}$ in order to cancel out the influence of the variation in the properties of the sample.

Within approximately $500 \mathrm{~min}$, a very significant difference between the results of the oedometer test and triaxial $K_{0}$ consolidation test is observed. This is not a fundamental difference between them because it was caused by the testing method. Instantaneous loading adopted in the ordinary oedometer tests was not available 
in the triaxial $K_{0}$ consolidation tests. The reason was that the specimen was required to be uniform and the feedback system required some time lag. In this study, the axial pressure was gradually increased to a target value in 3 $\mathrm{h}$. We compared the behaviors in the secondary consolidation stage because the initial $3 \mathrm{~h}(180 \mathrm{~min})$ were negligible when we focussed on the long-term consolidation behavior.

In the case of the normal consolidation range ( $p=646$ $\mathrm{kPa}$ ), both curves obtained from the two types of tests were compared thoroughly. However, in the case of the overburden effective stress $(p=358 \mathrm{kPa})$, the difference between the results of the two types of tests tends to increase with elapsed time.

One of the reasons why $r$ increases is that the $K_{0}$ value increases during the secondary consolidation. Figure 8 shows the temporal variations in the $K_{0}$ value. In this figure, the peculiar behavior in the initial $3 \mathrm{~h}(180 \mathrm{~min})$ is negligible, as mentioned above. In Fig. 6, $r$ tends to increase significantly with time in the overconsolidation range. The $K_{0}$ value, however, gradually increases with time for all the tests in the normal consolidation and overconsolidation ranges.

An increase in the $K_{0}$ value under a constant vertical stress implies an increase in the lateral stress in the specimen. If the coefficient of friction is assumed to be constant during the long-term consolidation tests, the increase in $K_{0}$ is closely related to the increase in the frictional pressure loss and probably one of the major factors responsible for the frictional pressure loss. In the overconsolidation range, the frictional pressure loss ratio increases more rapidly than the $K_{0}$ value. This fact indicates that the major factor for the frictional pressure loss in the overconsolidation range is a type of adhesion rather than the effective lateral stress.

\section{Summary of Friction Effect}

The frictional pressure loss ratio generally exceeds 0.2 when the consolidation pressure is less than approximately $300 \mathrm{kPa}$, rather than the overconsolidation range.

Because the compressive strain in the overconsolidation range is very small, the influence of the frictional

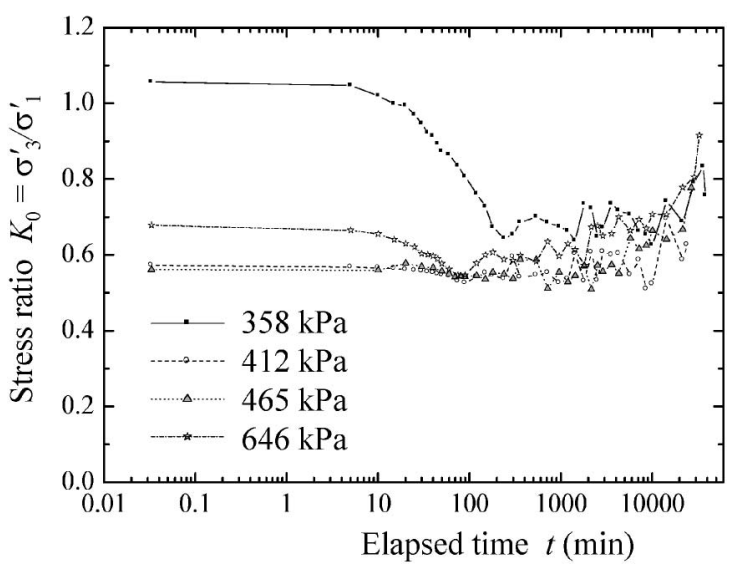

Fig. 8. Temporal variations of $K_{0}$ value pressure loss on the prediction of the consolidation settlement is significantly limited in engineering practice. However, in the normal consolidation range, the frictional pressure loss tended to increase with time, but it did not increase significantly with logarithmic time in the longterm consolidation test, indicating that the friction effect was almost in a steady state. Therefore, we thought that no correction was required for the test results using the oedometer with a rigid consolidation ring in the practical prediction of the long-term consolidation settlement. The frictional pressure loss was thought to be caused by an increase in either the effective stress or some type of cohesion. The test results indicated that the latter was significantly dominant in the overconsolidation range.

From the abovementioned quantitative results of the frictional pressure loss, we decided not to consider the friction effect in the following part, but each specimen size was limited to a thickness of $20 \mathrm{~mm}$. A series of interconnected type consolidation tests, in which each specimen element was individually loaded, was carried out to investigate the influence of the specimen thickness. This decision is consistent with the previous studies (Imai and Tang, 1992; Tanaka, 2005), in which the inter-connected type consolidation tests were carried out using soil specimen elements with a thickness less than $20 \mathrm{~mm}$.

\section{INFLUENCE OF SPECIMEN THICKNESS ON CONSOLIDATION BEHAVIOR}

\section{Inter-connected Type Consolidation Test}

A series of inter-connected type consolidation tests were carried out in order to investigate the influence of the soil thickness on the long-term consolidation behavior. As illustrated in Fig. 9, each soil specimen element was individually loaded such that the friction effect was minimized. The equipment used in this study was the same as that used by Tanaka (2005). The tests were carried out for specimen thicknesses of $20 \mathrm{~mm}(\mathrm{H} 2)$, consisted of 2 elements with a thickness of $10 \mathrm{~mm}$, and $100 \mathrm{~mm}$ (H10), consisted of 5 elements with a thickness of $20 \mathrm{~mm}$,
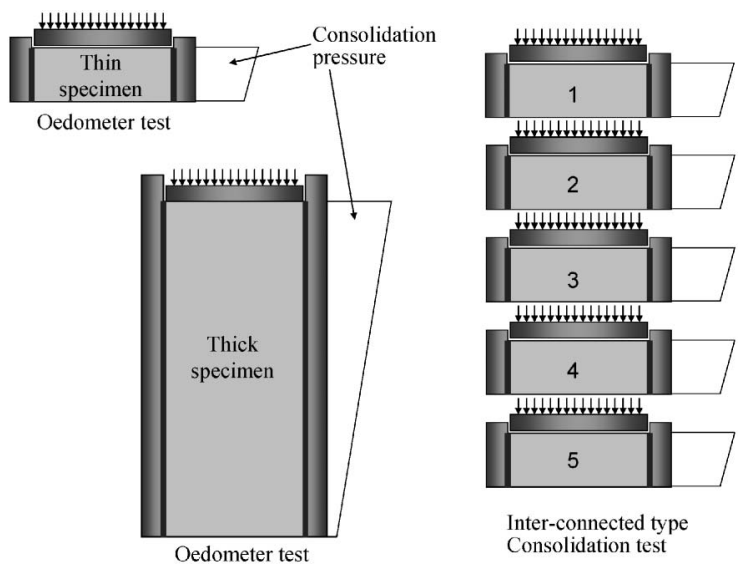

Fig. 9. Illustration of the friction effect in the oedometer test and inter-connected consolidation test 
in the single drainage boundary condition. For the sample Ma11 described below, specimen thicknesses of 50 $\mathrm{mm}$ (H5), consisted of 5 elements with a thickness of 10 $\mathrm{mm}$, and $200 \mathrm{~mm}(\mathrm{H} 20)$, consisted of 10 elements with a thickness of $20 \mathrm{~mm}$, were also examined.

The soil samples examined were undisturbed Ma13, Ma12, and Ma11 retrieved from the seabed of the Kansai International Airport and reconstituted Ma13 (denoted as Ma13Re). The physical and consolidation properties of the clay samples are listed in Table 3 . It should be noted that the retrieval depth of Ma12 was different from that in Table 1. Also, the retrieval depth of Ma13Re was different from that of Ma13. The retrieved sample was trimmed using a wire saw such that it had a diameter of $60 \mathrm{~mm}$ and a height of approximately $15 \mathrm{~mm}$ (or $25 \mathrm{~mm}$ ). Then it was inserted into a rigid stainless steel ring with an inner diameter of $60 \mathrm{~mm}$ and a height of $10 \mathrm{~mm}$ (or 20 $\mathrm{mm}$ ), and both ends were trimmed off. The trimmed specimen elements were individually inserted into the consolidation rings, and the inter-connected consolidometer was assembled. The equipment is illustrated in Fig. 10.

Each consolidometer was filled with deaired water and

Table 3. Physical and consolidation properties of the clay samples for the inter-connected consolidation test

\begin{tabular}{lrrcc}
\hline Sample name & Ma13 & Ma12 & Ma11 & Ma13Re \\
\hline Undisturbed & Yes & Yes & Yes & No \\
Reconstituted & No & No & No & Yes \\
Depth $z(\mathrm{CDL}-\mathrm{m})$ & 30 & 63 & 85 & - \\
Overburden effective stress $\sigma_{\mathrm{v} 0}^{\prime}(\mathrm{kPa})$ & 65 & 291 & 489 & - \\
Consolidation yield stress $p_{\mathrm{c}}(\mathrm{kPa})$ & 106 & 452 & 701 & 116 \\
Overconsolidation ratio $\mathrm{OCR}$ & 1.63 & 1.55 & 1.43 & - \\
Soil particle density $\rho_{\mathrm{s}}\left(\mathrm{g} / \mathrm{cm}^{3}\right)$ & 2.67 & 2.67 & 2.67 & 2.70 \\
Liquid limit $w_{\mathrm{L}}(\%)$ & 91.2 & 104.6 & 85.9 & 91.3 \\
Plastic limit $w_{\mathrm{P}}(\%)$ & 37.2 & 40.5 & 25.6 & 30.4 \\
Plasticity index $I_{\mathrm{p}}$ & 54.0 & 64.1 & 60.3 & 60.9 \\
Natural water content $w_{\mathrm{n}}(\%)$ & 83.3 & 82.2 & 51.5 & 75.2 \\
\hline
\end{tabular}

a backpressure of 98 or $196 \mathrm{kPa}$ was applied. The top piston of a consolidometer and the bottom base metal of one of the other consolidometers were connected by a copper tube through a porous metal disk with a diameter of $55 \mathrm{~mm}$. The drainage copper tubes for all the consolidometers were connected in series. The drainage system had a bypass to switch the connection to pallalel by valve operation. On each base drainage, a pore water pressure transducer (capacity of $3500 \mathrm{kPa}$ and accuracy of $0.88 \mathrm{kPa}$ ) was installed. The consolidation pressure was applied into the pressure cell above the loading piston with an o-ring.

The test conditions are listed in Table 4. In the preliminary consolidation stages, the consolidation pressure was incrementally loaded up to the overburden effective stress $\sigma_{\mathrm{v} 0}^{\prime}$. In this stage, the drainages were switched to bypass in parallel connection to create the double drainage boundary for all the specimen elements. This condition was maintained for $24 \mathrm{~h}$; then, the drainage was switched to series by valve operation, and the consolidation pressure was increased to a target pressure $\left(1.5 p_{\mathrm{c}}\right.$ or $\left.2 p_{\mathrm{c}}\right)$. Therefore, the loading condition is close to the real one in the subsoil layer subjected to the reclamation of the Kansai International Airport. Settlement and pore water pressure were measured for each specimen element. The settlement was measured by a gap sensor (capacity of $2 \mathrm{~mm}$ and accuracy of $0.0005 \mathrm{~mm}$ ) installed at the top of the consolidometer.

The main differences from the previous studies (Imai and Tang, 1992; Tanaka, 2005) are summarized below: a) Clay samples used in this study and Tanaka (2005) were undisturbed ones, while those in Imai and Tang (1992) were reconstituted ones; b) Imai and Tang (1992), and Tanaka (2005) focused on the strain rate effect, while this study focuses on the settlement; c) In Imai and Tang (1992), the loading was started at $24 \mathrm{~h}$ or EOP in series drainage connection. In Tanaka (2005), the duration of the preliminary consolidation was varied as proportional
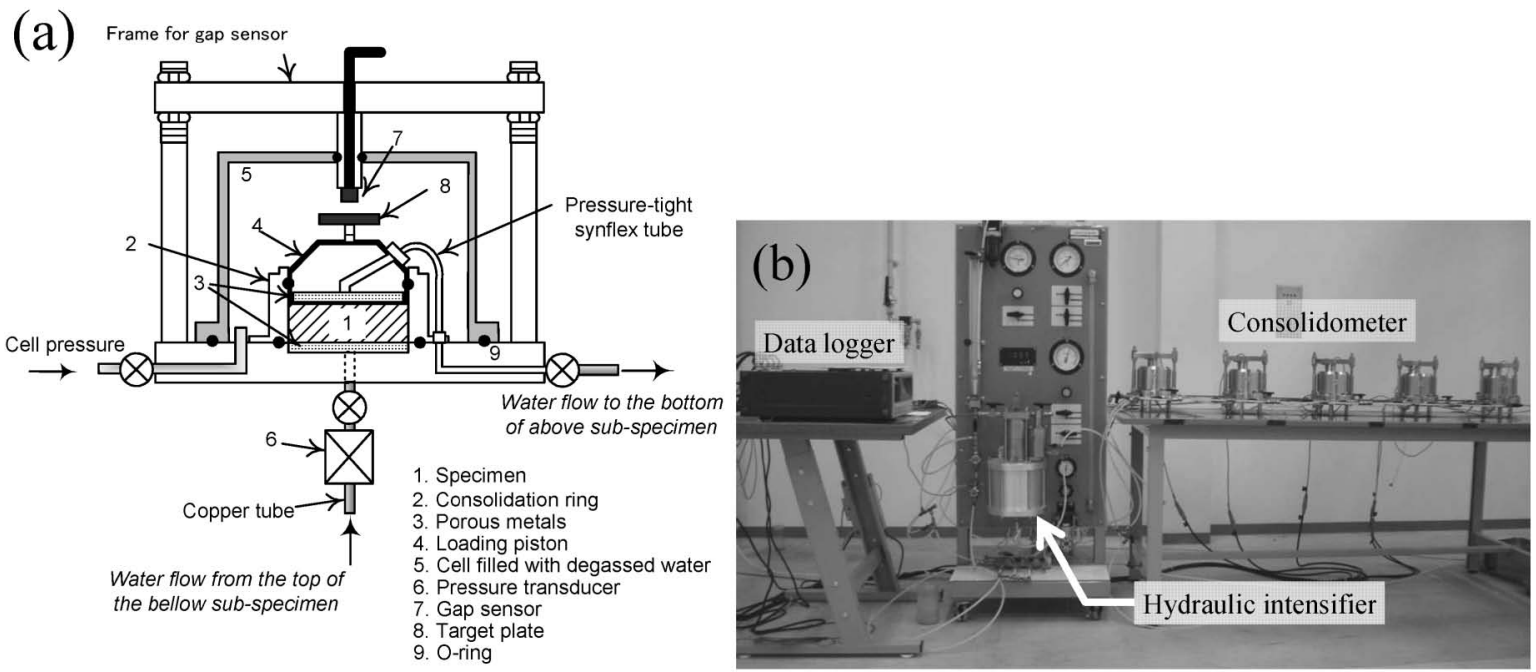

Fig. 10. Schematic layout of the inter-connected consolidation apparatus: (a) illustration of the consolidation cell and (b) photograph of the test apparatus 
Table 4. Test conditions for the inter-connected consolidation test

\begin{tabular}{|c|c|c|c|c|c|}
\hline \multirow[b]{2}{*}{ Sample } & \multirow[b]{2}{*}{$\begin{array}{c}\text { Specimen } \\
\text { thickness } \\
(\mathrm{mm})\end{array}$} & \multicolumn{2}{|c|}{ Pressures for preliminary consolidation } & \multirow[b]{2}{*}{$\begin{array}{l}\text { Target pressure } \\
\text { for long term } \\
\text { consolidation } \\
\quad(\mathrm{kPa})\end{array}$} & \multirow[b]{2}{*}{$\begin{array}{c}\text { Back pressure } \\
(\mathrm{kPa})\end{array}$} \\
\hline & & $\begin{array}{c}\text { Preliminary } \\
\text { consolidation } \\
\text { pressure for } 24 \mathrm{~h} \\
(\mathrm{kPa})\end{array}$ & $\begin{array}{l}\text { Overburden } \\
\text { effective stress } \\
\text { for } 7 \text { days } \sigma_{\mathrm{v} 0}^{\prime} \\
(\mathrm{kPa})\end{array}$ & & \\
\hline Ma13 & 20,100 & $39 \rightarrow$ & $69 \rightarrow$ & $216\left(=2 p_{\mathrm{c}}\right)$ & 98 \\
\hline Ma12 & 20,100 & $39 \rightarrow$ & $291 \rightarrow$ & $904\left(=2 p_{\mathrm{c}}\right)$ & 196 \\
\hline Ma11 & $20,50,100,200$ & $59 \rightarrow$ & $489 \rightarrow$ & $1080\left(=1.5 p_{\mathrm{c}}\right)$ & 196 \\
\hline Ma13Re & 20,100 & $20 \rightarrow$ & $88 \rightarrow$ & $235\left(=2 p_{\mathrm{c}}\right)$ & 98 \\
\hline
\end{tabular}
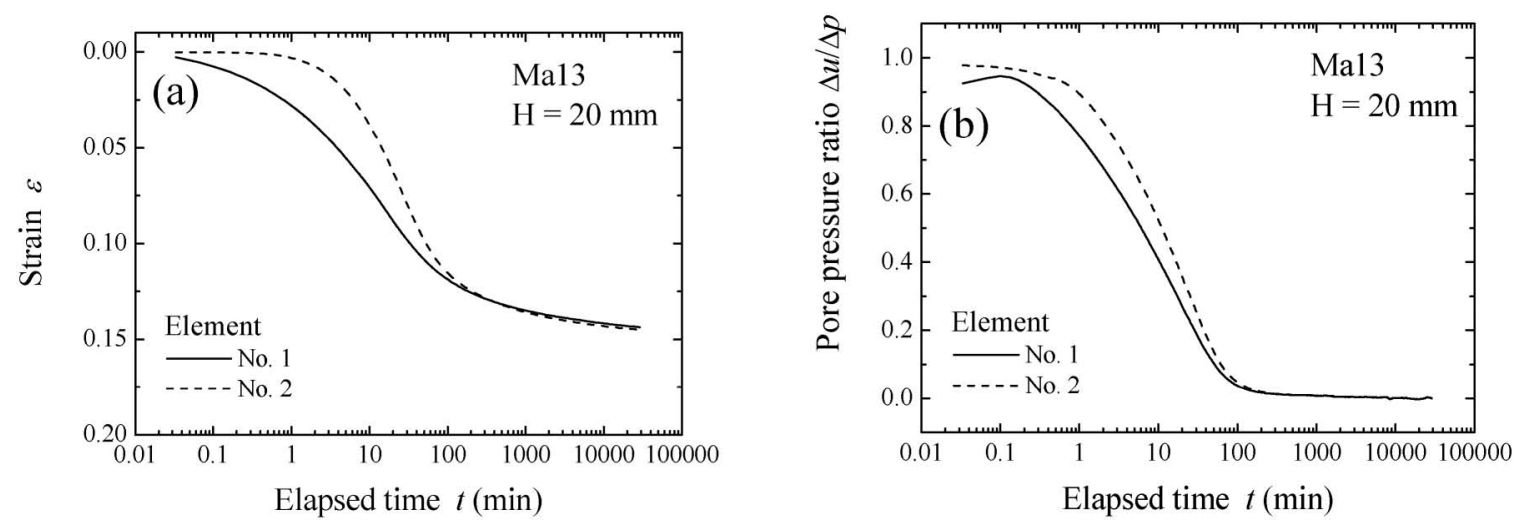

Fig. 11. Temporal variations in the (a) compressive strain and (b) excess pore pressure in each specimen element for Ma13 (H2)
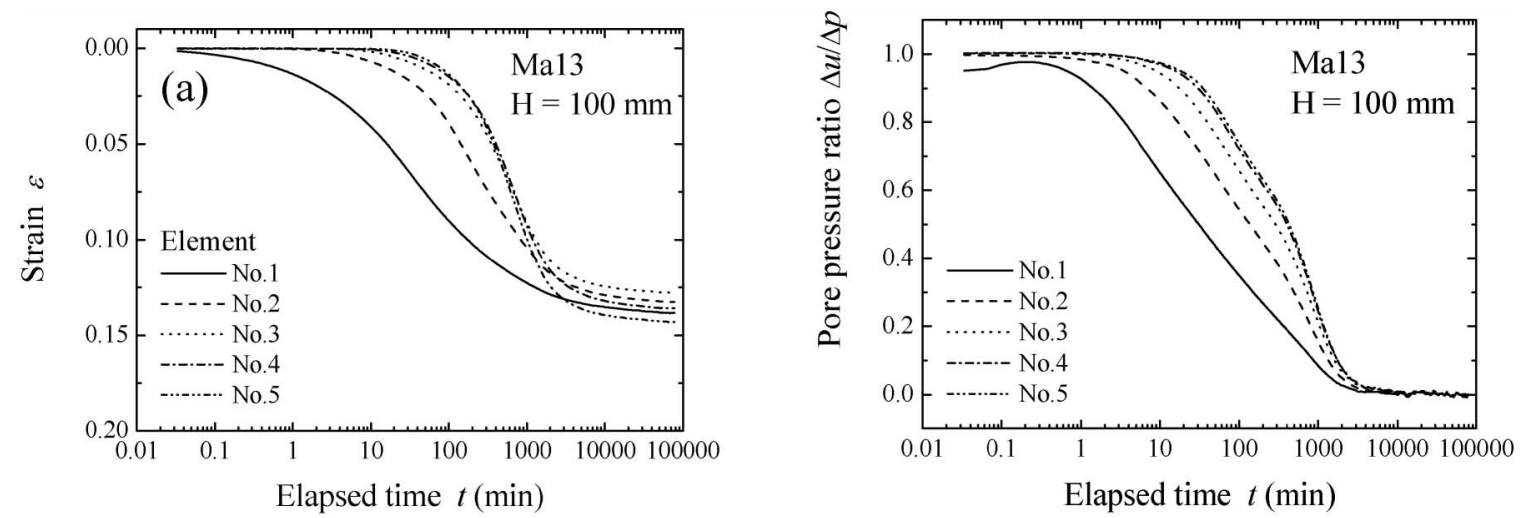

Fig. 12. Temporal variations in the (a) compressive strain and (b) excess pore pressure in each specimen element for Ma13 (H10)

to the squared $H$ in series drainage connection. In this study, the duration of the preliminary consolidation was $24 \mathrm{~h}$ in bypass drainage condition; d) The consolidation pressure was raised up from $156.8 \mathrm{kPa}$ to $313.6 \mathrm{kPa}$ (normal consolidation range) in Imai and Tang (1992), from $2.0 p_{\mathrm{c}}$ to $3.0 p_{\mathrm{c}}$ (normal consolidation range) or from $\sigma_{\mathrm{v} 0}^{\prime}$ to $p_{\mathrm{c}}$ (over consolidation range) in Tanaka (2005), and from $\sigma_{\mathrm{v} 0}^{\prime}$ to $1.5 p_{\mathrm{c}}$ or $2.0 p_{\mathrm{c}}$ (real condition in the subsoil layer) in this study. Therefore, this study can discuss the thickness effect from the different point of view, which can directly imagine the consolidation behavior of the subsoil under the Kansai International Airport.

\section{Test Results}

The temporal variations in the (a) compressive strain and (b) excess pore water pressure in each specimen element are shown in Figs. 11-20. The excess pore pressure dissipation and increase in consolidation strain were more rapid at a specimen element closer to the drainage (element No. 1 was the closest to the drainage). The times when the excess pore water pressures completely dissipated were the same for all the specimen elements in each test. It can be explained that the drained water from the upstream specimen element flowed into the downstream specimen element. From this point of view, the EOP was clearly identified in the excess pore water pressure dissipation rather than in the compressive strain for all the tests. In particular, the EOP on the compressive strain for the tests with a thick specimen ( $\mathrm{H} 5$ and $\mathrm{H} 10)$ was clearer than that for the tests with a thin specimen (H2). Furthermore, 

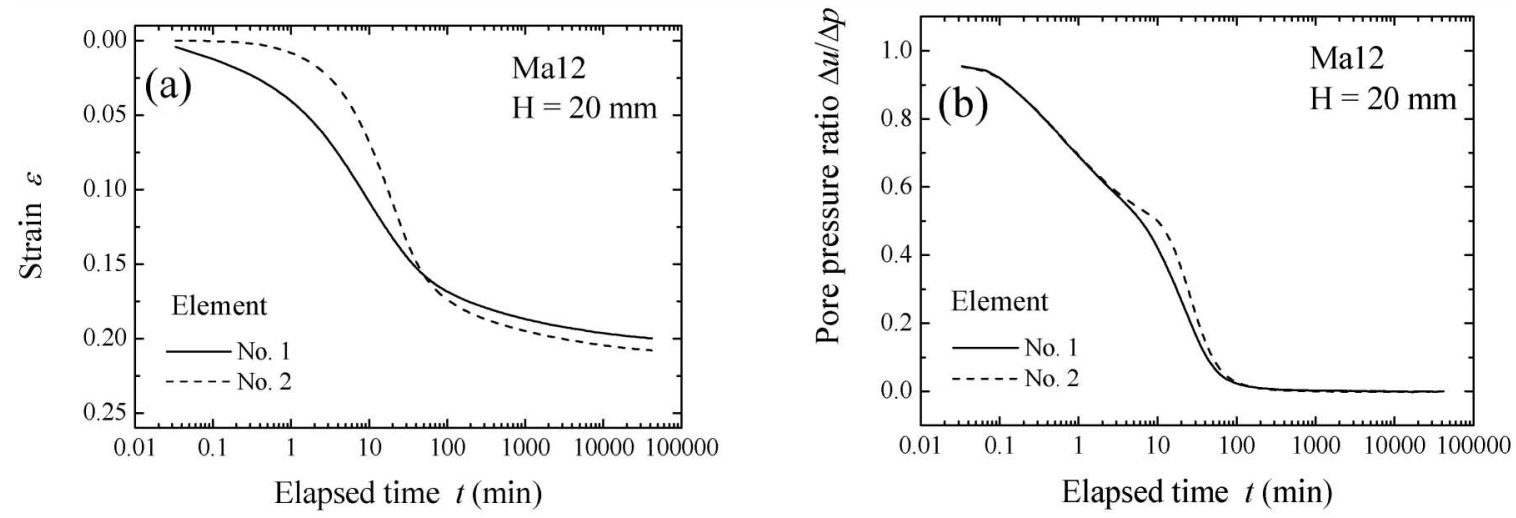

Fig. 13. Temporal variations in the (a) compressive strain and (b) excess pore pressure in each specimen element for Ma12 (H2)
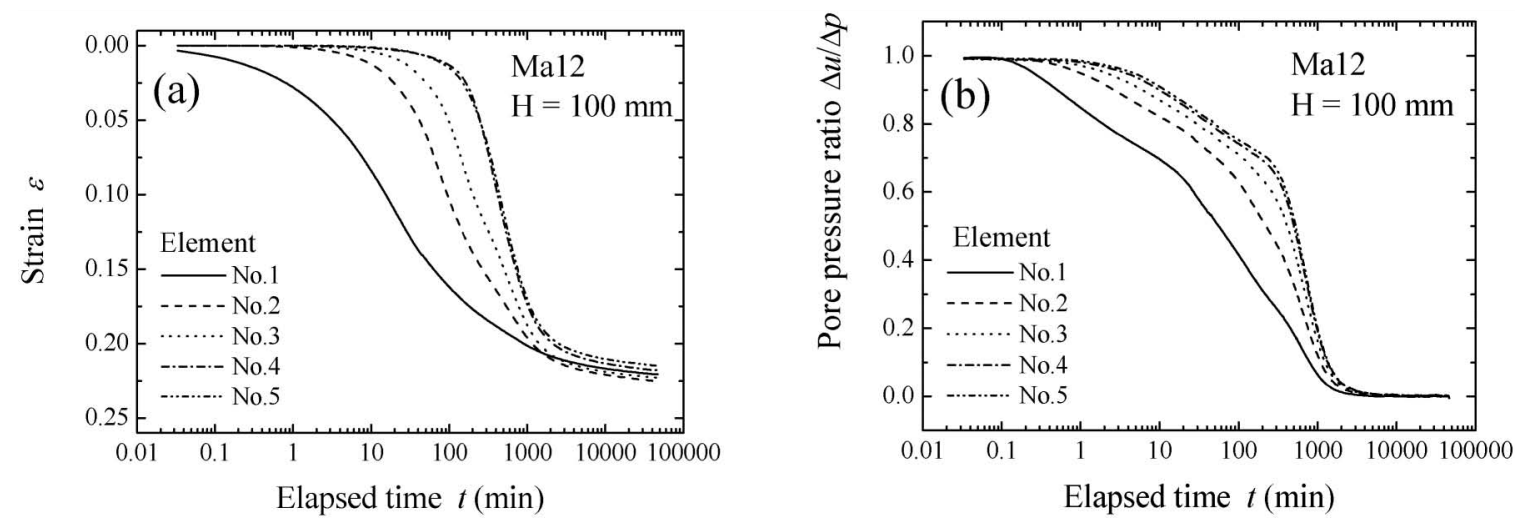

Fig. 14. Temporal variations in the (a) compressive strain and (b) excess pore pressure in each specimen element for Ma12 (H10)
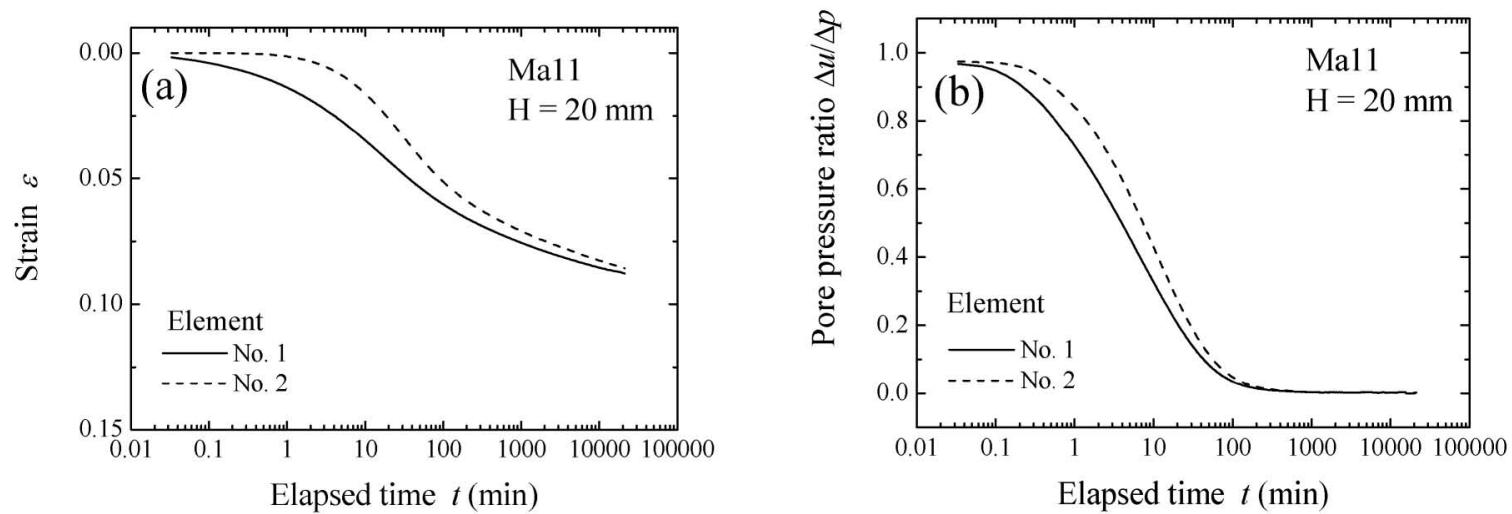

Fig. 15. Temporal variations in the (a) compressive strain and (b) excess pore pressure in each specimen element for Ma11 (H2)

focusing on the strain behavior of each specimen element, the strain in an element closer to the drainage boundary, particularly specimen element number " 1 ,", shows an unclear EOP.

The excess pore pressure dissipations of all the specimen elements were in the order of the distance from the drainage boundary; however, strains were not necessarily in the same order. As mentioned above, the excess pore pressures were in good order caused by the inflow from the upstream specimen element, even if the specimen elements were not perfectly homogeneous. Because the strain was strongly influenced by small differences in the soil properties, the strains were not always in a good order for natural clay deposits, which generally had variable properties. However, if the observed strain was divided by the strain corresponding to the EOP at almost the completion of the excess pore water pressure dissipation (e.g., 98\%), we confirmed that the strains are also in a good order. The orderly strain behavior corresponding to the distance from the drainage boundary indicated that the inter-connected consolidation tests were conducted with sufficiently high quality and accuracy. 

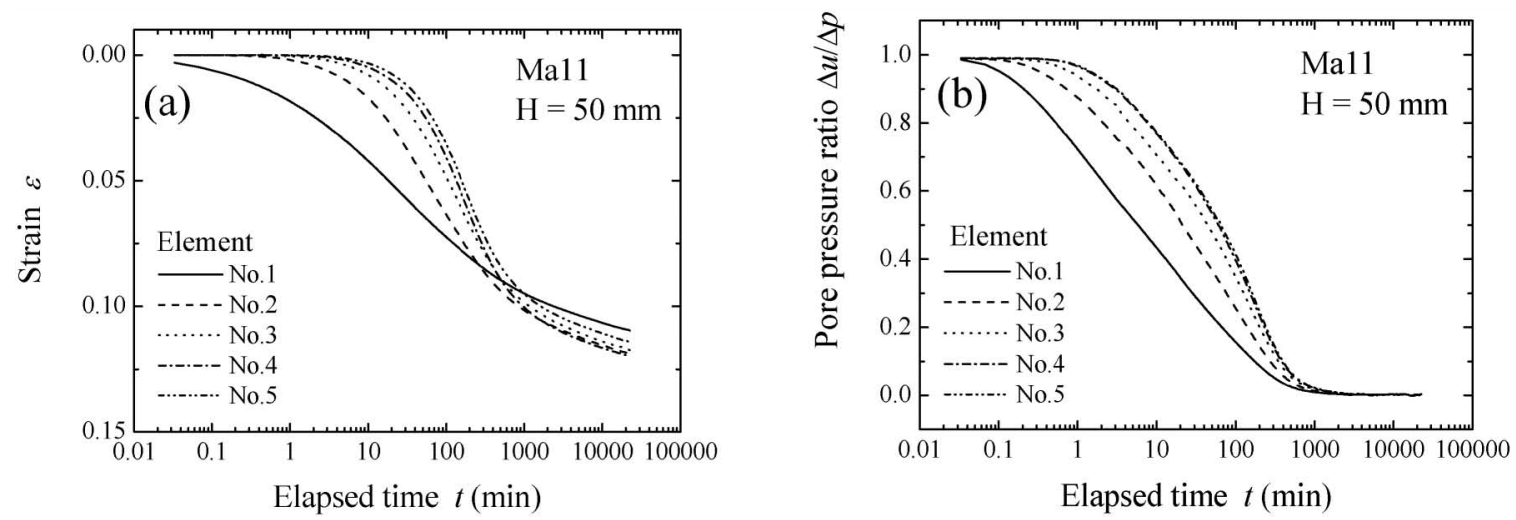

Fig. 16. Temporal variations in the (a) compressive strain and (b) excess pore pressure in each specimen element for Ma11 (H5)
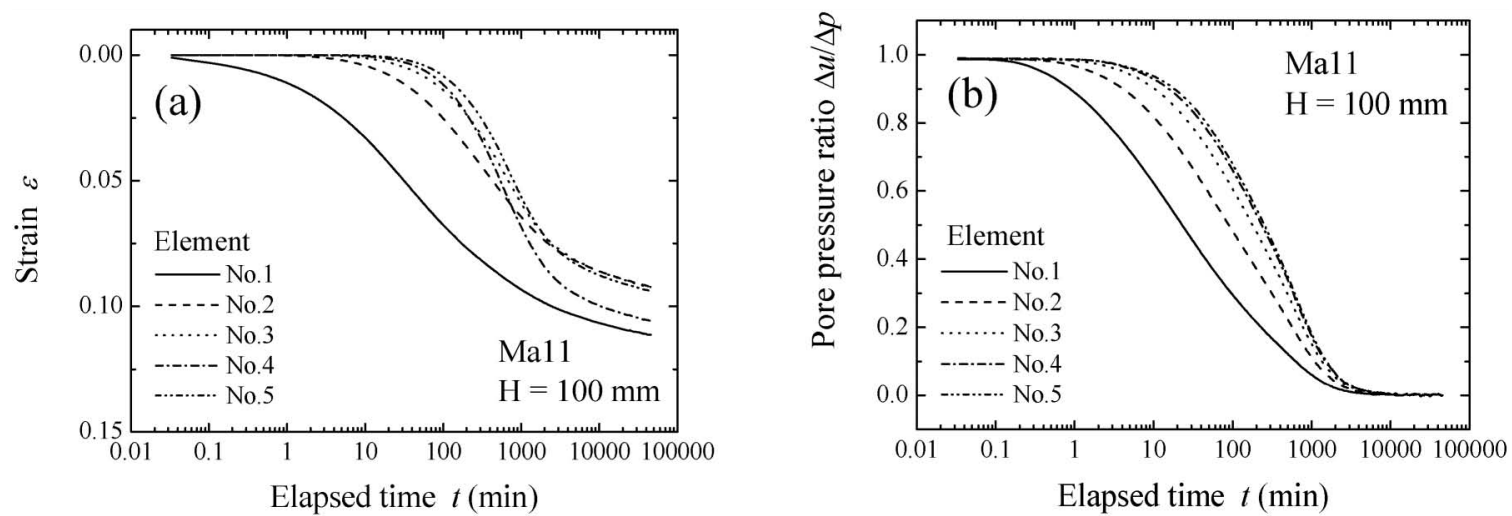

Fig. 17. Temporal variations in the (a) compressive strain and (b) excess pore pressure in each specimen element for Ma11 (H10)
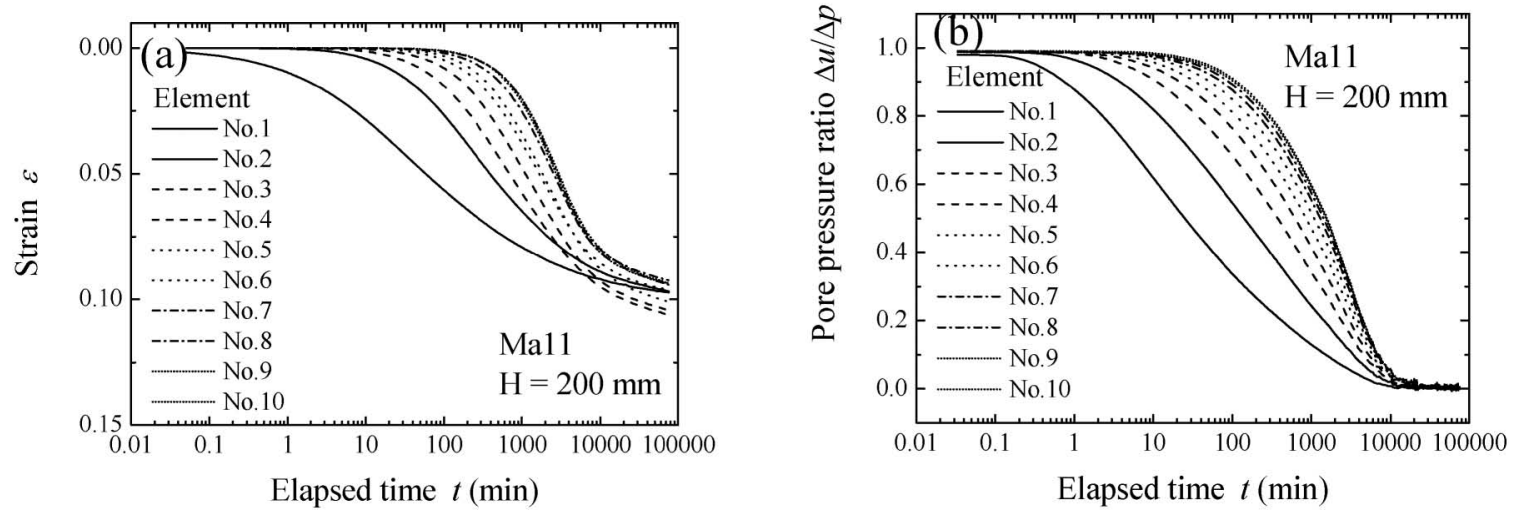

Fig. 18. Temporal variations in the (a) compressive strain and (b) excess pore pressure in each specimen element for Ma11 (H20)

\section{Thickness Effect}

The temporal variations in the (a) compressive strain defined for the total thickness (not for the thickness of each specimen element) and (b) excess pore water pressure measured at the undrained boundary (at the larger specimen number) are shown in Figs. 21-24. For each sample, test results with different thicknesses were superimposed. Here, the elapsed time $t$ was divided by the squared maximum drainage distance $H$, i.e., $t / H^{2}$, where $H$ was defined as the thickness just before the long-term loading. This is equivalent to time factor $T_{\mathrm{v}}$ divided by the coefficient of consolidation $c_{\mathrm{v}}$, i.e., $T_{\mathrm{v}} / c_{\mathrm{v}}$.

In Ma13 and Ma13Re, the excess pore water pressures and the compressive strains observed in the primary consolidation stage for different thicknesses were equivalent, indicating that the law of squared $H$ was perfectly satisfied. However, in Ma12 and Ma11, some significant differences at different thicknesses were seen in the strains. At the excess pore water pressures, the results for different thicknesses agreed well against $t / H^{2}$, indicating that the time corresponding to the EOP was consistent with the law of squared $H$. 

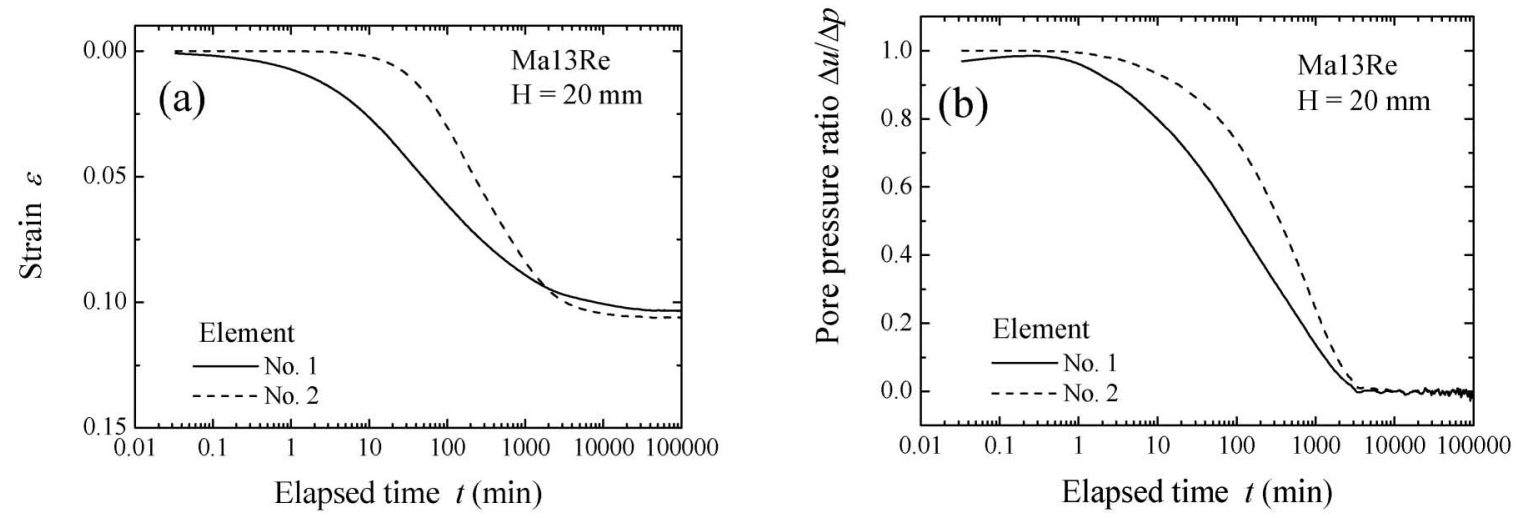

Fig. 19. Temporal variations in the (a) compressive strain and (b) excess pore pressure in each specimen element for Ma13Re (H2)
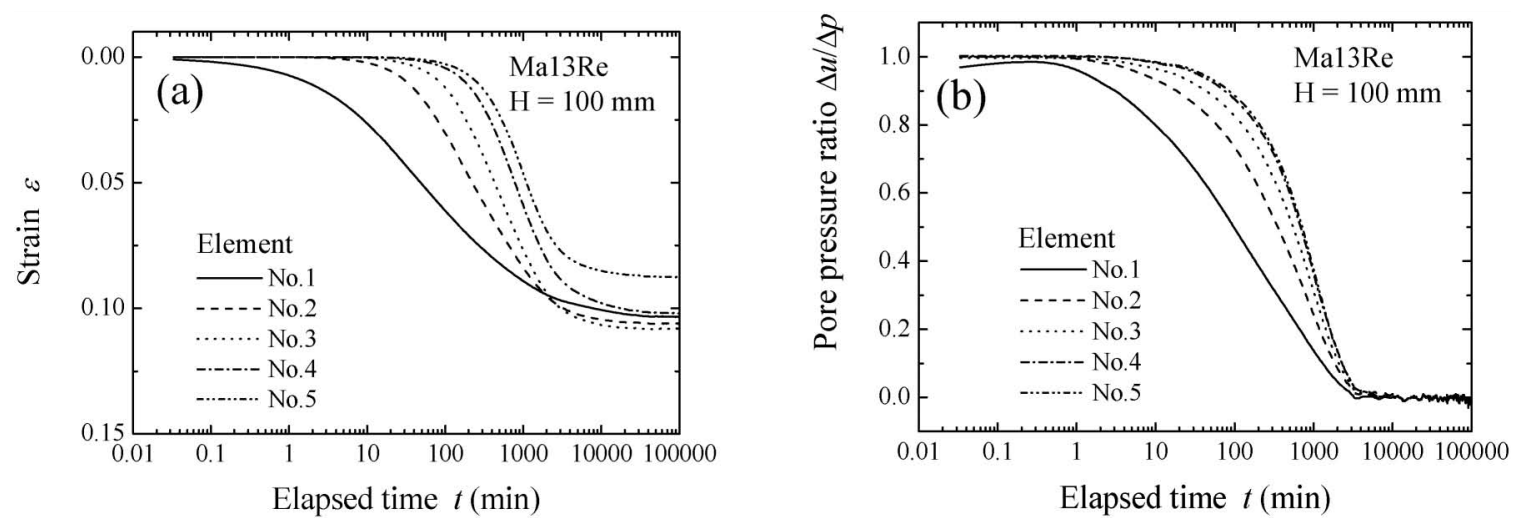

Fig. 20. Temporal variations in the (a) compressive strain and (b) excess pore pressure in each specimen element for Ma13Re (H10)
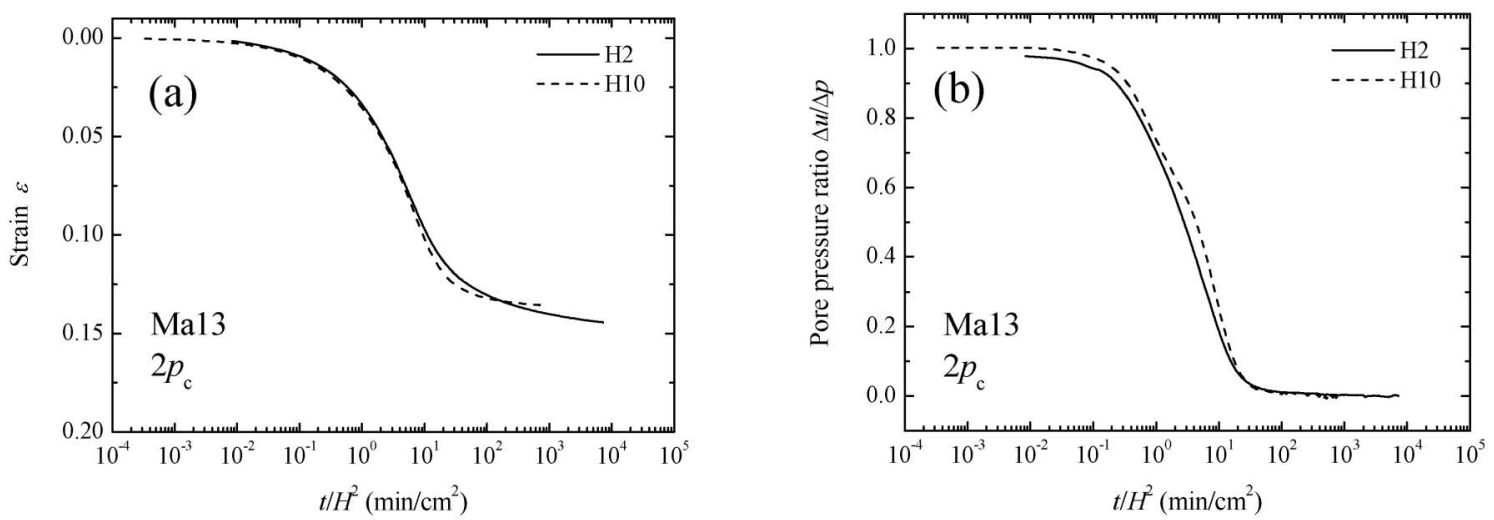

Fig. 21. Temporal variations in the (a) compressive strain defined for the total thickness and (b) excess pore pressure measured at the undrained boundary for Ma13

In Ma13 and Ma13Re, the behavior was classified into hypothesis A, as shown in Fig. 1. However, in Ma12 and Ma11, the strain for a specimen thickness of $20 \mathrm{~mm}(\mathrm{H} 2)$ was significantly smaller than that for the others, and this fact was close to hypothesis B. From these tendencies, we can understand that the strain behavior following hypothesis B appeared when the clay sample had a developed structure. However, in Ma11, the strains for specimen thicknesses of $50 \mathrm{~mm}$ (H5), $100 \mathrm{~mm}$ (H10), and 200 $\mathrm{mm}(\mathrm{H} 20)$ were almost equivalent. This indicated that the strain variation with time followed the hypothesis A for specimens with larger thicknesses.

The drainage distance of the single drainage $20-\mathrm{mm}$ specimen (H2) is twice of that of the double drainage 20-mm specimen (denote as $\mathrm{H} 1$ because it corresponds to the single drainage $10-\mathrm{mm}$ specimen), which is routinely used for the incremental loading oedometer test in practice. Note here that $\mathrm{H} 1$ specimen was not tested in this study. Settlement strains in $\mathrm{H} 2$ and $\mathrm{H} 5$ are related by the hypothesis $\mathrm{B}$, indicating that those in $\mathrm{H} 1$ and $\mathrm{H} 5$ are also 

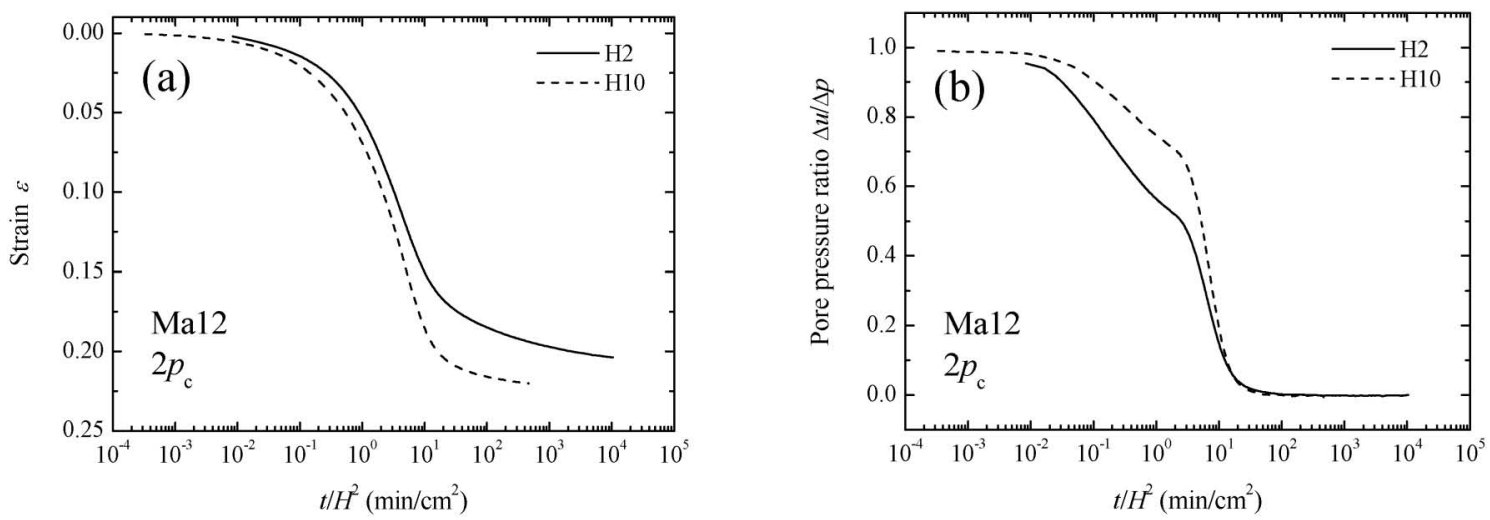

Fig. 22. Temporal variations in the (a) compressive strain defined for the total thickness and (b) excess pore pressure measured at the undrained boundary for Ma12
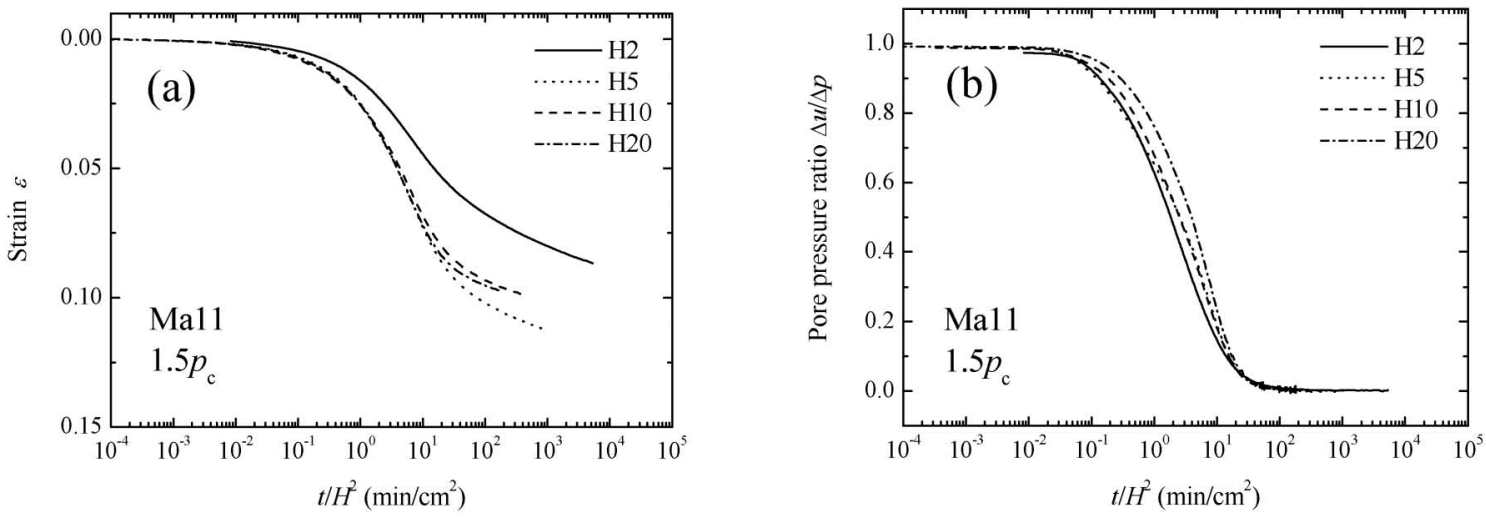

Fig. 23. Temporal variations in the (a) compressive strain defined for the total thickness and (b) excess pore pressure measured at the undrained boundary for Ma11
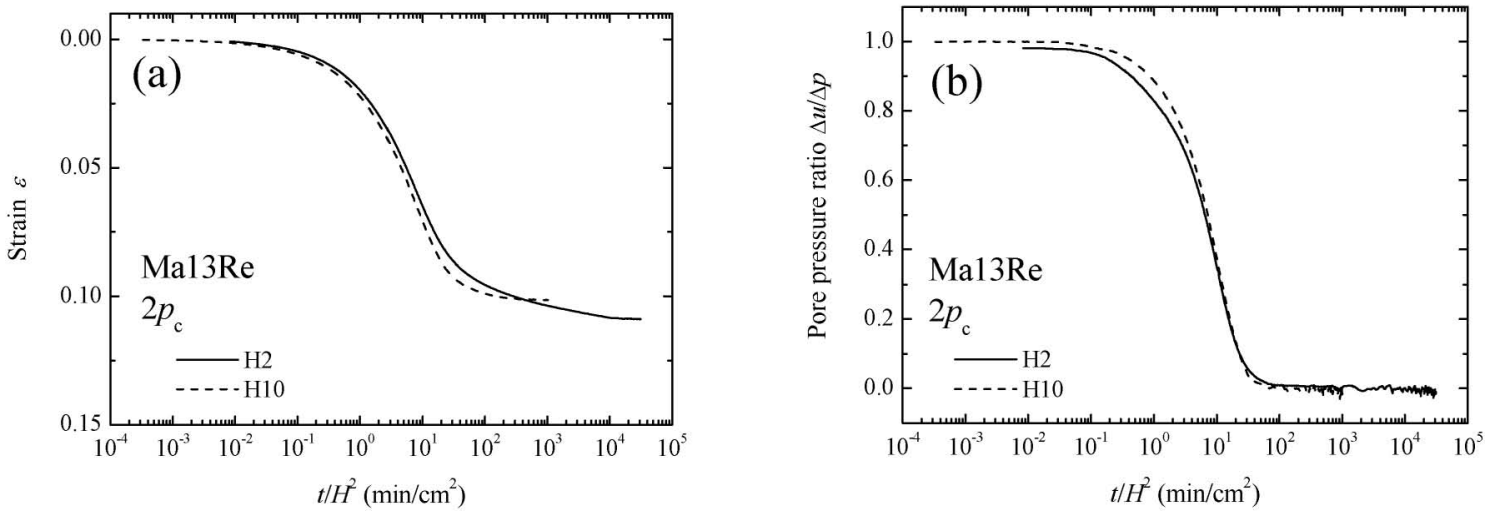

Fig. 24. Temporal variations in the (a) compressive strain defined for the total thickness and (b) excess pore pressure measured at the undrained boundary for Ma13Re

related by the hypothesis B. Meanwhile, those in $\mathrm{H} 5, \mathrm{H} 10$ and $\mathrm{H} 20$ are related by the hypothesis A. $\mathrm{H} 10$ and $\mathrm{H} 20$ have thicknesses of respectively 2 and 4 times of H5. This fact indicates that the thickness effect for the real subsoil layer, which has a larger thickness, is very limited. Therefore, the hypothesis B is valid at a certain level between the consolidation behaviors of $\mathrm{H} 1$ specimen and the in situ subsoil layer. In a case of structured clay, the in situ primary consolidation settlement tends to be underestimated by using the test result for $\mathrm{H} 1$ specimen, because the strain for $\mathrm{H} 2$ is approximately $30 \%$ smaller than that for $\mathrm{H} 5, \mathrm{H} 10$, and $\mathrm{H} 20$ at $t / H^{2}=1 \times 10^{2} \mathrm{~min} / \mathrm{cm}^{2}$ in Fig. 23(a).

In the hypothesis $\mathrm{A}$, the secondary consolidation occurs only after the end of primary consolidation (EOP), while in the hypothesis B, the secondary consolidation 
occurs during the primary consolidation. When the specimen thickness is significantly small such as $\mathrm{H} 2$, the primary consolidation proceeds very rapidly, resulting in that the secondary consolidation is not identified during the primary consolidation. However, if it is the only reason for that, the settlement behavior for $\mathrm{H} 5, \mathrm{H} 10$, and H20 should also be related by the hypothesis B rather than the hypothesis A. Also, it cannot be explained that $\mathrm{H} 2$ and $\mathrm{H} 10$ of unstructured clays (Ma13 and Ma13Re) are related by the hypothesis A. The highly structured clays such as Ma12 and Ma10 probably show significantly high strain rate dependency during a process of brittle structural collapsing. Therefore, the primary consolidation behavior was apparently related by the hypothesis B because of the structural collapsing rather than the viscosity.

In the following part, we will discuss the test results for Ma11 in greater detail. The specimen elements trimmed from an undisturbed sample were not perfectly homogeneous. There were some variations in the grain size distribution reflecting the sedimentary environments. Therefore, it was difficult to accurately evaluate the difference between the strain behaviors of the specimen elements. Using the strain divided by the strain at the EOP is a concept to minimize the effect of heterogeneity; however, our concern is that the essential difference between them also disappears.

Therefore, we decided to use the void ratio of each specimen element just before the long-term loading (i.e., initial void ratio denoted as $e_{\mathrm{i}}$ hereafter) as an index representing the condition of each specimen element. The relationship between $e_{\mathrm{i}}$ of each specimen element and specimen thickness (maximum drainage distance) $H$ is shown in Fig. 25. All the specimens were collected from almost the same depth; however, the initial void ratios $e_{\mathrm{i}}$ show some variation in a range of 1.21-1.31 because of sample heterogeneity. The values of $e_{\mathrm{i}}$ could possibly be classified into two groups at the boundary of $e_{\mathrm{i}}=1.25$.

The relationship between the decremental void ratio change $\Delta e$ and the initial void ratio $e_{\mathrm{i}}$ is shown in Fig. 26. Hereafter, the EOP is defined as $98 \%$ dissipation of the excess pore water pressure $\Delta u$, the strain at the EOP is denoted as $\varepsilon_{\mathrm{EOP}}$, and the void ratio change during the primary consolidation $(\Delta e)$ is defined as $\Delta e=e_{\mathrm{i}}-e_{\mathrm{EOP}}$. The void ratio change $\Delta e$ tends to increase linearly in a range of $e_{\mathrm{i}}>1.25$, while $\Delta e$ does not show a clear tendency in the range of $e_{\mathrm{i}}<1.25$. Therefore, the specimen elements can be classified corresponding to $e_{\mathrm{i}}$, whether it was greater or lesser than 1.25.

The relationship between $\Delta e / e_{\mathrm{i}}$ and $H$ is shown in Fig. 27. The value of $\Delta e / e_{\mathrm{i}}$ increases with the thickness $H$ for the specimen elements in $e_{\mathrm{i}}<1.25$, while it stays almost constant or increases slightly for those in $e_{\mathrm{i}}>1.25$. For the specimen elements in $e_{\mathrm{i}}<1.25$, the tendency is consistent with the large-scale consolidation tests reported in Aboshi (1973). However, for specimen elements in $e_{\mathrm{i}}$ $>1.25$, the tendency is consistent with the experimental data with EOP-concept reported by Mesri and Choi (1985).

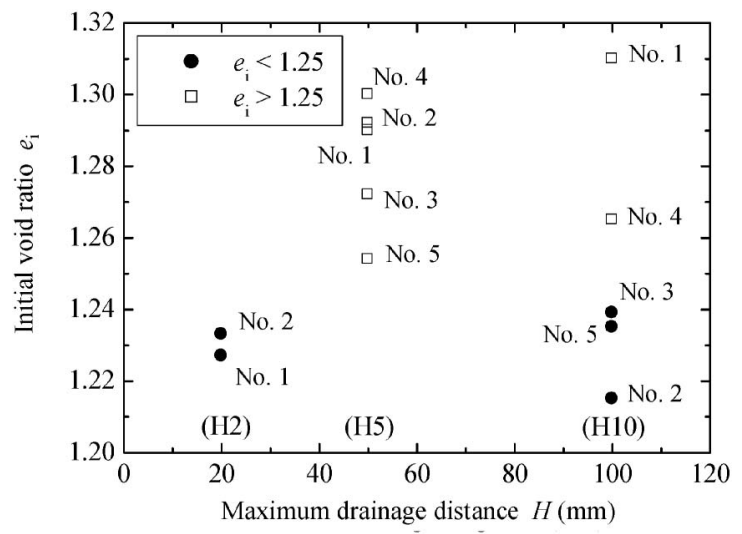

Fig. 25. Relationship between $e_{\mathrm{i}}$ of each specimen element and maximum drainage distance $H$

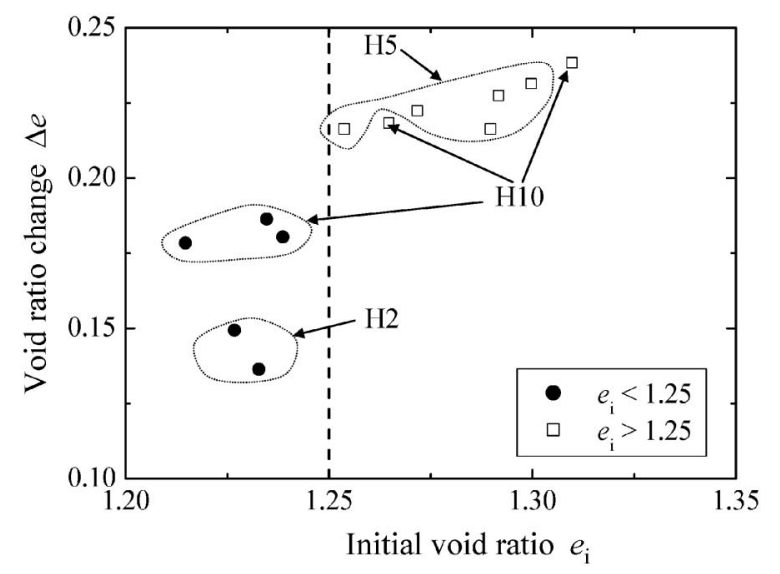

Fig. 26. Relationship between decremental void ratio change $\Delta e$ and initial void ratio $e_{\mathrm{i}}$

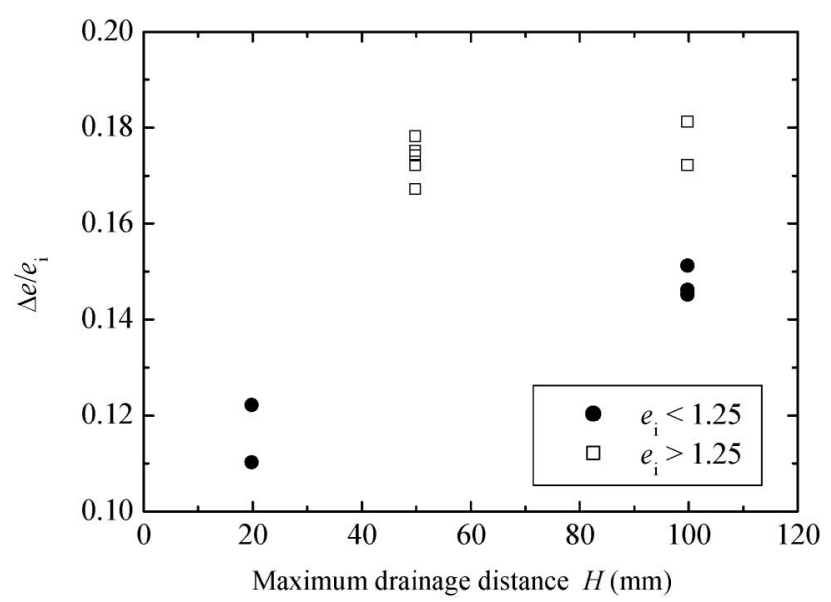

Fig. 27. Relationship between $\Delta e / e_{\mathrm{i}}$ and $H$ for Ma11

The relationships between $\Delta e / e_{\mathrm{i}}$ and $H$ for all the samples (Ma13, Ma12, Ma11, and Ma13Re) are shown in Fig. 28. In not only Ma11 but also the other samples, the void ratio change $\Delta e / e_{\mathrm{i}}$ tends to stay almost constant or increase, but never decreases, with $H$.

As abovementioned, the hypothesis A is valid for not 


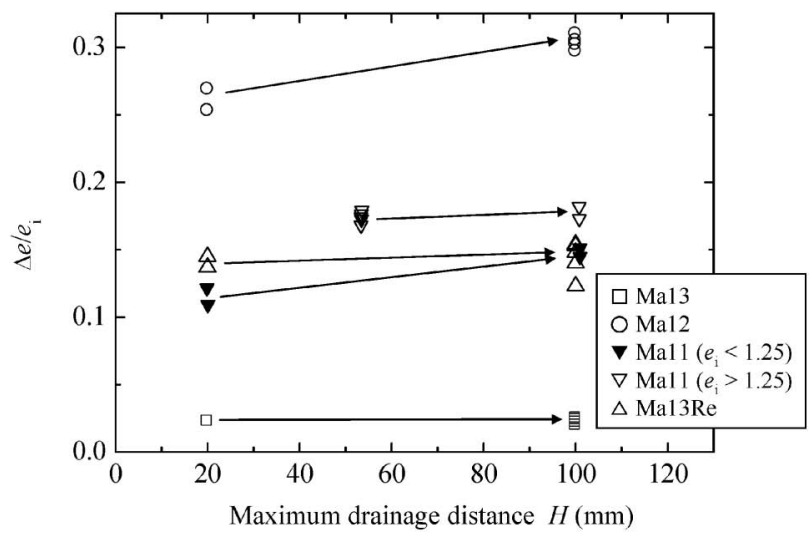

Fig. 28. Relationships between $\Delta e / e_{\mathrm{i}}$ and $H$ for all the samples

only the unstructured clays (Ma13 and Ma13Re) with any thicknesses but also the structured clays (Ma11 and probably even Ma12) with a thickness larger than a certain value (more than $50 \mathrm{~mm}$ in the inter-connected type consolidation test). In a precise sense, however, the value slightly tends to increase with the specimen thickness $H$, indicating that the real behavior is mainly the hypothesis A but it is slightly coupled with the hypothesis B.

\section{Homogeneity of Specimen Elements}

The consolidation behavior in each specimen element is discussed in greater detail. The strain at the EOP is denoted here as $\varepsilon_{\mathrm{EOP}}$. The coefficient of volume compressibility $m_{\mathrm{v}}$ is defined as $m_{\mathrm{v}}=\varepsilon_{\mathrm{EOP}} / \Delta p$, where $\Delta p$ is the stress increment. As shown in Fig. 29(a), we took an element numbered " $n$," and the water flow change in the element $\left(\Delta q_{n}\right)$ was calculated as the difference between the inflow from the upstream element $\left(q_{n}\right)$ and the outflow to the downstream element $\left(q_{n-1}\right)$, i.e., $\Delta q_{n}=q_{n-1}-q_{n}$. The pore water pressure change in the element $\left(\Delta u_{n}\right)$ was also calculated as the difference between the upstream and downstream pressures ( $u_{n}$ and $u_{n-1}$, respectively), i.e., $\Delta u_{n}=u_{n}-u_{n-1}$. Subsequently, the hydraulic conductivity $k_{2}$ under this consolidation pressure was calculated by Darcy's law as follows:

$$
k_{2}=\frac{\Delta q_{n}}{A} \cdot \frac{H_{n} \rho_{\mathrm{w}} g}{\Delta u_{n}}
$$

where $A$ is the cross sectional area, $\rho_{\mathrm{w}}$ is the pore water density, $g$ is the gravitational acceleration, and $H_{n}$ is the thickness of the $n$th element.

Because the hydraulic conductivity changes with the effective stress corresponding to the pore pressure dissipation, its representative value $k$ for the consolidation stage is defined as the geometrical average of $k_{1}$ at the overburden effective stress (just before long-term loading) and $k_{2}$ at the long-term consolidation pressure (at EOP of longterm loading), i.e., $k=\sqrt{k_{1} \times k_{2}}$. The value of $k_{1}$ could not be obtained from the inter-connected type consolidation test. Therefore, we derived a $\log p^{\prime}-\log k$ relationship separately from the CRS consolidation test. The value of $k_{2}$ was calculated as the slope of the convergence line, as shown in Fig. 29(b). The coefficient of consolidation $c_{\mathrm{v}}$ (a)

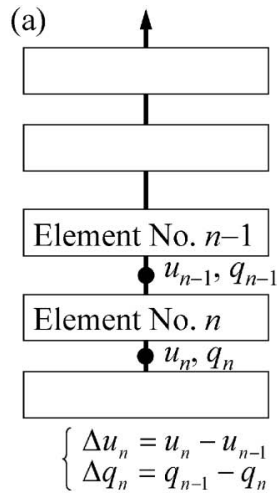

Fig. 29. Definitions of (a) differential excess pore pressure $\Delta u$ and flow rate $\Delta q$ in an element and (b) hydraulic conductivity $k$

was calculated from $m_{\mathrm{v}}$ and $k$, i.e., $c_{\mathrm{v}}=k /\left(m_{\mathrm{v}} \rho_{\mathrm{w}} g\right)$.

The consolidation parameters $m_{\mathrm{v}}, k$, and $c_{\mathrm{v}}$ are evaluated for each specimen element, and their depth profiles are shown in Fig. 30. The vertical axis $z / H$ is the depth $z$ normalized by the specimen thickness (maximum drainage distance) $H$. The consolidation parameters of each specimen element were evaluated by the abovementioned method. The element closest to the drainage boundary exhibits slightly different values. This is probably caused by rapid dissipation with a very high hydraulic gradient and very high flow velocity. It is noteworthy that $m_{\mathrm{v}}$ and $c_{\mathrm{v}}$ at the $2 \mathrm{nd}, 3 \mathrm{rd}$, and 5 th elements from the drainage boundary for $\mathrm{H} 10$ are close to the data for $\mathrm{H} 2$, corresponding to the elements in $e_{\mathrm{i}}<1.25$. Further, the values of $k$ for all the tests are very uniform. Therefore, we can say that the specimen elements can be classified into two groups but are very homogeneous for the whole depths. This fact is consistent with the homogeneity of the Osaka Bay clay investigated through CRS consolidation test for specimens trimmed at depths of $25 \mathrm{~mm}$ as reported by Watabe et al. (2007).

\section{Behavior around Yield Stress $p_{\mathrm{c}}$}

In Ma12, the temporal variations in the compressive strain followed a normal pattern; however, the excess pore pressure dissipation curves were characterized by an unusual pattern consisting of 2 stages (Figs. 13, 14, and 22). The excess pore pressure ratio $\Delta u / \Delta p$ suddenly decreased to around 0.7 at the beginning of the consolidation process and then decreased to zero in the usual manner.

Tanaka (2005) pointed out the existence of small burrows that serve as vertical drains. The pore pressure decreases suddenly once; after the burrows collapse, the pore-water pressure increases substantially. However, by performing a visual examination and a pore pressure sensitivity examination, we confirmed that the Ma12 sample had no burrows when the backpressure was applied to the specimen. Therefore, there were other causes of the characterized pore pressure dissipation pattern.

Leroueil et al. (1980) obtained a similar and clearer pore pressure dissipation pattern for sensitive eastern Canada clay with a significantly developed structure. In 

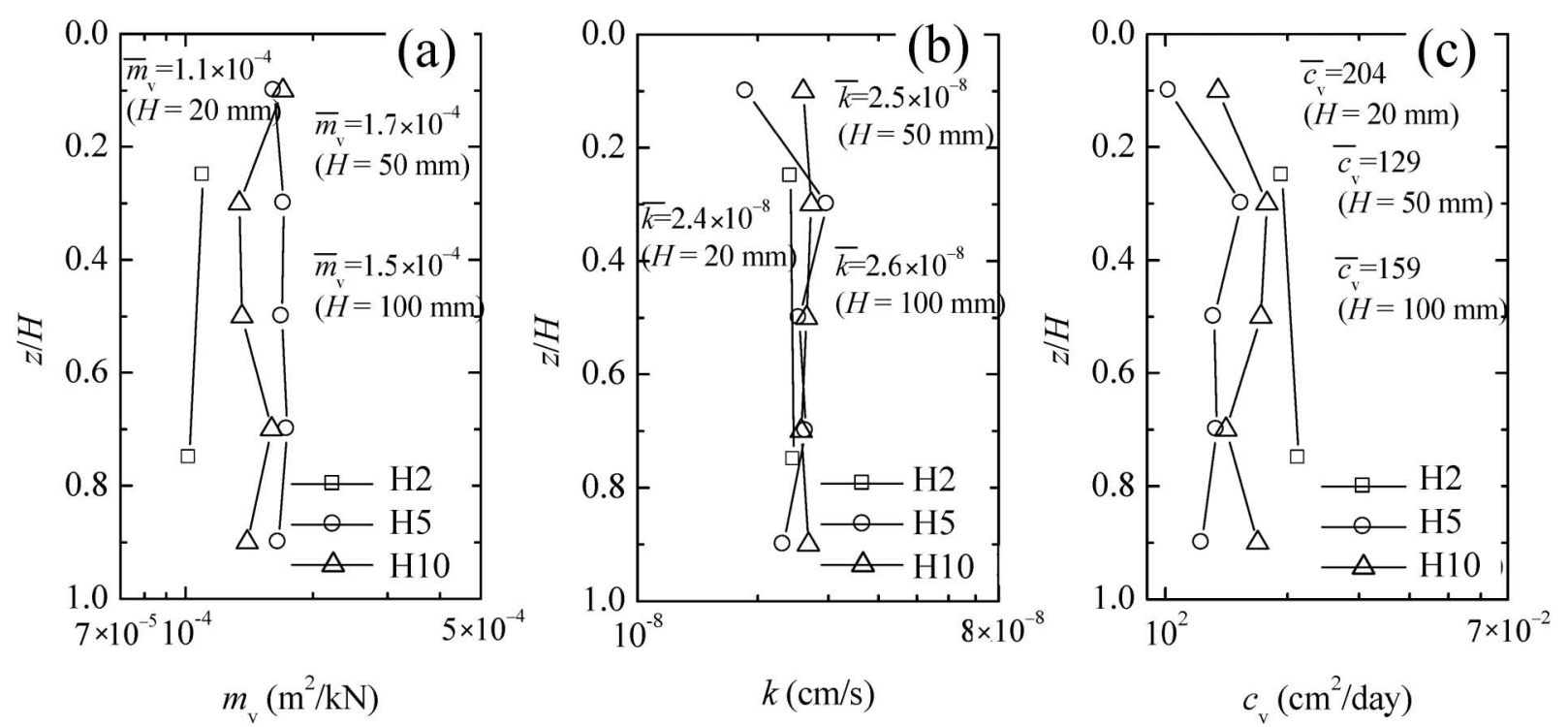

Fig. 30. Depth profiles of consolidation parameters $m_{\mathrm{v}}, k$, and $c_{\mathrm{v}}$ evaluated for each specimen element

their explanation for this behavior, the sudden dissipation at the beginning corresponded to a larger coefficient of consolidation in the overconsolidation range and the consequent slow dissipation corresponded to a smaller coefficient of consolidation in the normal consolidation range. Because Ma12 had a high water content with a higher developed structure, the explanation of the behavior can be the same as that of Leroueil et al. (1980).

\section{Summary of Specimen Thickness Effect}

The EOP can be clearly identified in the excess pore pressure dissipation. However, the EOP becomes unclear in the strains when the specimen thickness decreases. The law of squared $H$ is essentially valid for the pore water pressure dissipation. The highly structured clays such as Ma12 and Ma10 probably show significantly high strain rate dependency during a process of structural collapsing. Therefore, the primary consolidation behavior was apparently related by the hypothesis B, because of the structural collapsing rather than the viscosity. The hypothesis A is valid for not only the unstructured clays (Ma13 and Ma13Re) with any thicknesses but also the structured clays (Ma11 and probably even Ma12) with a thickness larger than a certain value (more than $50 \mathrm{~mm}$ in the interconnected type consolidation test). In a precise sense, however, the value slightly tends to increase with the specimen thickness $H$, indicating that the real behavior is mainly the hypothesis A but it is slightly coupled with the hypothesis B. In addition, consolidation parameters $m_{\mathrm{v}}$, $k$, and $c_{\mathrm{v}}$ for each specimen element of the inter-connected type consolidation test are evaluated and their values, particularly $k$, have a small variation through the whole thickness.

\section{CONCLUSIONS}

In this study, consolidation tests with frictional pres- sure loss measurement, triaxial $K_{0}$ consolidation tests, and inter-connected type consolidation tests were carried out and their results were discussed. The inter-connected type consolidation tests were carried out for specimens with thicknesses of 20 to $200 \mathrm{~mm}$. The loading pressure was raised from $\sigma_{v 0}^{\prime}$ to $1.5 p_{\mathrm{c}}$ or $2.0 p_{\mathrm{c}}$, simulating the real condition in the subsoil under the reclamation of the Kansai International Airport. The following conclusions are valid for the range of the limited thicknesses, but we believe that those are extensively applicable to the thickness effect between in situ and laboratory consolidation behaviors.

1) For the Osaka Bay clays retrieved from the Kansai International Airport, the frictional pressure loss ratio exceeds 0.2 , when the consolidation pressure is less than $300 \mathrm{kPa}$.

2) In the overconsolidation range, the frictional pressure loss is significant. From an engineering sense, however, the friction effect is not significant because the compressive strain is very small in the overconsolidation range.

3) In practical applications of the long-term consolidation test, data correction in association with the friction effect is not required.

4) The frictional pressure loss is possibly caused by an increase in either the effective stress or some sort of cohesion. The test results indicate that the latter is significantly dominant in the overconsolidation range.

5) The EOP can be clearly identified in the excess pore pressure dissipation. However, the EOP becomes unclear in the strains when the specimen thickness decreases.

6) The law of squared $H$ is essentially valid for the pore water pressure dissipation in specimens with various thicknesses (20 to $200 \mathrm{~mm}$ ).

7) For clay samples without a developed structure, the 
strain variation follows hypothesis A. However, for clay samples with a developed structure, the strain variation follows hypothesis B. Even in the latter case, when we compare specimens with larger thicknesses, the strain variations follow hypothesis A.

8) The compressive strain at the EOP remains constant or increases slightly with the specimen thickness. This fact is apparently consistent with the EOP concept proposed by Mesri and Choi (1985), but it is not strictly valid. This fact indicates that the creep compression occurs even during the dissipation of excess pore water pressure and is governed by structural viscosity.

9) The highly structured clays such as Ma12 and Ma10 probably show significantly high strain rate dependency during a process of structural collapsing. Therefore, the primary consolidation behavior was apparently related by the hypothesis B because of the structural collapsing rather than the viscosity. The hypothesis $\mathrm{A}$ is valid for not only the unstructured clays (Ma13 and Ma13Re) with any thicknesses but also the structured clays (Ma11 and probably even Ma12) with a thickness larger than a certain value (more than $50 \mathrm{~mm}$ in the inter-connected type consolidation test). In a precise sense, however, the value slightly tends to increase with the specimen thickness $H$, indicating that the real behavior is mainly the hypothesis A but it is slightly coupled with the hypothesis B.

10) Consolidation parameters $m_{\mathrm{v}}, k$, and $c_{\mathrm{v}}$ for each specimen element in the inter-connected type consolidation test can be evaluated. The values obtained for Ma11, particularly $k$, have a small variation through the entire thickness of the specimen examined.

11) In Ma12, the excess pore pressure dissipation curves are characterized by an unusual pattern with two stages. The excess pore pressure ratio $\Delta u / \Delta p$ suddenly decreases to 0.7 at the beginning of the consolidation process and then decreases to zero in a usual manner. Because Ma12 has a high water content with a highly developed structure, the sudden dissipation at the beginning corresponds to a larger coefficient of consolidation in the overconsolidation range and the consequent slow dissipation corresponds to a smaller coefficient of consolidation in the normal consolidation range.

\section{ACKNOWLEDGEMENTS}

The study presented in this paper was carried out as a part of the collaborative research between Port and Airport Research Institute (PARI) and Kansai International Airport Land Development Co., Ltd. (KALD). We would like to acknowledge Mr. T. Fushimi, a former stu- dent of Yokohama National University, for his assistance on this study.

\section{REFERENCES}

1) Aboshi, H. (1973): An experimental investigation on the similitude in the consolidation of a soft clay, including the secondary creep settlement, Proc. 8th ICSMFE, Moscow, 4(3), p88.

2) Berre, T. and Iversen, K. (1972): Oedometer tests with different specimen heights on a clay exhibiting large secondary compression, Géotechnique, 22(1), 53-70.

3) Imai, G. and Tang, Y.-X. (1992): A constitutive equation of onedimensional consolidation derived from inter-connected tests, Soils and Foundations, 32(2), 83-96.

4) Imai, G., Tanaka, Y. and Saegusa, H. (2003): One-dimensional consolidation modeling based on the isotach law for normally consolidated clays, Soils and Foundations, 43(4), 173-188.

5) Jamiolkowski, M., Ladd, C. C., Germaine, J. T. and Lancellotta, R. (1985): New developments in field and laboratory testing of soils. Proc. 11th ICSMFE, San Francisco, 1, 57-153.

6) Ladd, C. C., Foott, R., Ishihara, K., Schlosser, F. and Poulos, H. G. (1977): Stress-deformation and strength characteristics. Stateof-the-Art Report, Proc. 9th ICSMFE, Tokyo, 2, 421-494.

7) Leroueil, S., Le Bihan, J. P. and Tavenas, F. (1980): An approach for the determination of the preconsolidation pressure in sensitive clays, Can. Geotech. J., 17(3), 446-453.

8) Leroueil, S. (2006): The isotache approach. Where are we 50 years after its development by Professor Šuklje? (2006 Prof. Šuklje's Memorial Lecture), 13th Danube-European Conference on Geotechnical Engineering, Ljubljana 2006, 55-88.

9) Mesri, G. and Choi, Y. K. (1985): The uniqueness of the end-of-primary (EOP) void ratio-effective stress relationship, Proc. 11th ICSMFE, San Francisco, 2, 587-590.

10) Okai, D., Mizumoto, K., Mekata, T., Kusumi, M., Rito, F. and Nosaka, T. (1999): An example of ring friction measured by means of specially designed large scale oedometer for a highly organic clay, Proc. 54th Annual Conf. JSCE, 3(A), 370-371 (in Japanese).

11) Sato, T., Ochiai, H., Hayashi, S. and Umezaki, T. (1999): Influence of side friction in the one-dimensional consolidation test, 24th Japan National Conf. Soil Mech. Found. Engrg., 389-392 (in Japanese).

12) Sivrikaya, O. and Togrol, E. (2006): Measurement of side friction between specimen and consolidation ring with newly designed oedometer cell, ASTM Geotech. Test. J., 29(1), 87-94.

13) Tanaka, H. (2005): Consolidation behavior of natural soils around $p_{\mathrm{c}}$ value-Inter-connected oedometer test, Soils and Foundations, 45(3), 97-105.

14) Tsuchida, T. and Kikuchi, Y. (1991): $K_{0}$ consolidation of undisturbed clays by means of triaxial cell, Soils and Foundations, 31(3), 127-137.

15) Watabe, Y., Tanaka, M., Tanaka, H. and Tsuchida, T. (2003): $K_{0^{-}}$ consolidation in a triaxial cell and evaluation of in-situ $K_{0}$ for marine clays with various characteristics, Soils and Foundations, 43(1), 1-20.

16) Watabe, Y., Shiraishi, Y., Murakami, T. and Tanaka, M. (2007): Variability of physical and consolidation test results for relatively uniform clay samples retrieved from Osaka Bay, Soils and Foundations, 47(4), 701-716.

17) Yamanouchi, T. and Yasuhara, K. (1975): Secondary compression of organic soils, Soils and Foundations, 15(1), 69-79.

18) Yin, J. H., Graham, J., Clark, J. L. and Gao, L. (1994): Modelling unanticipated pore-water pressures in soft clays, Can. Geotech. J., 31, 773-778. 